\title{
Lexical gaps and morphological decomposition: Evidence from German
}

\section{Swetlana Schuster}

\section{Aditi Lahiri}

University of Oxford

Corresponding author: Swetlana Schuster

Authors' institution and e-mail addresses:

Faculty of Linguistics, Philology and Phonetics

Clarendon Institute

Oxford OX1 2HG

University of Oxford, U.K.

E-mail: swetlana.schuster@ling-phil.ox.ac.uk

E-mail: aditi.lahiri@ling-phil.ox.ac.uk 


\section{Abstract}

On the evidence of four lexical decision tasks in German, we examine speakers' sensitivity to internal morphological composition and abstract morphological rules during the processing of derived words, real and novel. In a lexical decision task with delayed priming, speakers were presented with two-step derived nouns such as Heilung 'healing' derived from the adjective heil 'intact' via the verb heilen 'heal'. These were compared to two sets of derived novel words, one with and the other without an intermediate verb; e.g. *Spitzung 'sharpening' from spitz 'sharp' via spitzen 'sharpen' (Experiment 1) and *Hübschung 'beautifying' from hübsch 'pretty' via *hübschen 'beautify' (Experiment 2). The question was whether there would be a difference in the two types of novel words. Both sets were morphologically viable in terms of combinatory possibilities. Results indicated that extant and novel complex words activated their respective base forms; i.e. Heilung, *Spitzung, *Hübschung all primed heil, spitz, hübsch. Both sets of novel words were then combined in a third (delayed priming) experiment, where again they primed their bases, but were nevertheless significantly different from each other. Items with real words in the intermediate position (*Spitzung) showed stronger priming effects. Controls that were only related in form or semantics did not prime; neither did structurally unviable pseudowords show priming. A final experiment (Experiment 4), comparing the two types of novel words (*Spitzung vs. *Hübschung) in a simple lexical decision task, also revealed significant differences across these sets, suggesting that the lexical status of the intermediate derivation affects the processing of novel forms. 


\section{Keywords}

morphological complexity; delayed priming; lexical gaps; morphological rules; visual word recognition

\section{Highlights}

- First study investigating processing of multi-suffixed words and pseudowords

- Morphological processing independent of semantics and form overlap

- Morphological decomposition possible across lexical gaps in derivational paradigms

- Evidence for sensitivity to lexical composition within derivational chain 
Within the field of word recognition of complex words, an ongoing discussion has been whether complex derived words are holistic or decomposed and which factors determine decomposition, if any. This debate centres on the question whether we store every single word form (e.g. walk, walks, walker) holistically (Butterworth, 1983; Joanisse \& Seidenberg, 1999) or whether morphologically complex words are represented and in certain cases accessed through their morphological constituents (e.g. Taft \& Forster, 1975; Pinker \& Ullman, 2002; Clahsen, Sonnenstuhl, \& Blevins, 2002). A critical question in morphological processing thus concerns the role of purely morphological effects at different stages of visual word recognition and the interpretability of complex items.

At very early stages of visual word recognition, 'automatic' segmentation of morphologically complex words has been well established. Seminal work in masked priming (cf. Rastle, Davis, \& New, 2004) has shown that suffix-like items (e.g. -er) can be stripped off, leading to the activation of a word that is not necessarily morphologically related. For instance, corn was activated after seeing corner, but brothel failed to activate broth since -el is not an English suffix. This suggests that units that are recognised as suffixes can be 'stripped', even from items where they do not function as an affix, but where a correspondingly simpler word exists, regardless of its meaning. Evidence for this is substantiated by findings reported in Kazanina, Dukova-Zheleva, Geber, Kharmalov and Tonciulescu (2008). In this study, a masked priming experiment was used to investigate the processing of multi-affixed complex words in Russian. These consisted of a root morpheme to which a diminutive suffix $-\mathrm{k}$ was attached and which was followed by a case/numbermarking suffix. Transparent forms such as $\operatorname{gor}_{\text {Root }}-k_{D i m}-a_{N o m . S G}$ (N., 'little mountain') were decomposed as evidenced by a priming effect for the noun $\operatorname{gor}_{\text {Root }} a_{N o m . S G}(\mathrm{~N}$., 'mountain'). Pseudo-derived forms such as $\operatorname{lunk}_{\text {Root }} a_{\text {Nom.SG }}$ (N., 'hole') also primed a morphologically and semantically unrelated target such as $\operatorname{lun}_{\text {Root }}-a_{N o m . S G}(\mathrm{~N}$., 'moon'). Similarly to the findings 
reported in Rastle et al. (2004), form controls such as $\operatorname{part}_{\text {Root }}-a_{\text {Nom.SG }}$ (N., 'desk') failed to instantiate a priming effect for a form-related target $\operatorname{par}_{\text {Root }}-a_{N o m . S G}(\mathrm{~N} .$, 'pair'). These findings demonstrate that early decomposition effects are not limited to single-affixed forms and that word-internal suffixes (here the diminutive -k) can also be stripped. As shown by Crepaldi, Rastle and Davis (2010), the position of the affixes clearly plays a significant role as when suffixes such as -ness are added to the beginning of a word (i.e. if a suffix becomes a prefix

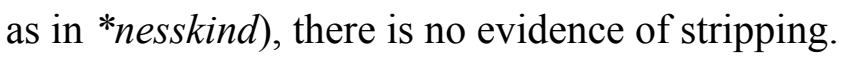

The question then arises to what extent this decomposition extends to pseudowords which are composed of existing stems and suffixes, but are not themselves words of a language. Longtin and Meunier (2005) pursued this idea in French comparing two sets of pseudowords consisting of stem and suffix such as *rapidifier versus *sportation where both consist of existing stems and affixes, but only *rapidifier has the acceptable combination of stem and suffix that follows the morphological rules of French. The suffix -ifier is a productive suffix in deriving verbs from adjectives, while -ation adds to verbs and does not productively derive nouns from nouns in Modern French. Comparable real words would be

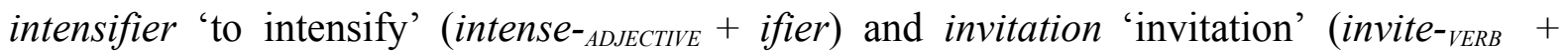
ation). An off-line semantic interpretability task showed that words like *rapidifier were judged to be interpretable, while the *sportation set elicited significantly lower interpretability ratings. Nevertheless, both sets of pseudowords elicited priming in a masked priming paradigm, suggesting that semantic interpretability was not taken into account at this early stage of word processing. Form-controls such as *rapiduit that consisted of an existing word and a non-suffix ending did not prime the embedded word rapide. This reinforces the interpretation that masked priming taps into morphological structure and cannot be reduced to a form-related effect. Note, however, that more recent masked priming studies using combined behavioural and event-related potential responses (Morris, Porter, Grainger, \& 
Holcomb, 2011) revealed priming effects for purely form-related pairs such as 'cornire' and 'corn' in English. Morris et al. (2011) argue that differences between the two studies can be attributed to divergences in the degree of overlap between prime and target across the two studies. What appears to be consistent across the two studies, however, is that morphological decomposition is independent of the semantic interpretability of the novel form in masked priming. In a cross-modal design using the same set of stimuli, however, Meunier and Longtin (2007) found that semantic interpretability modulated activation as priming was only observed for the *rapidifier set of words, but not for the *sportation set.

The notion of semantic interpretability or 'meaningfulness' in pseudowords composed of more than one morpheme was taken up extensively in Marelli and Baroni (2015). They present a computational model of morpheme combination at the meaning level that is based on co-occurrences of morphologically complex novel forms from a distributional semantics perspective. Affixes included suffixes (e.g. -able, -less), as well as prefixes (e.g., re-, un-). Derivations were varied including verb to adjective (e.g. sketchable vs. dawnable) and noun to adjective (e.g. acneless vs. hikeless). Forms like *acneless and *hikeless were presented to participants in off-line tasks for acceptability ratings. The results showed that forms that received high ratings of meaningfulness (e.g. *acneless) had more neighbours than those that were rated low (e.g. *hikeless). The computational model mirrors the off-line results in that meaningfulness of novel items is closely linked to the number of semantic neighbours.

Both Marelli and Baroni (2015) and Longtin and Meunier (2005) consider the effect of semantic interpretability on morphological processing. A crucial difference between their assumptions is related to the formation of their novel items. Marelli and Baroni (2015) strictly follow legal combinations of stem and affix; i.e. -less can attach to nouns and hence *acneless is a legal novel form. Longtin and Meunier (2005), however, included implausible combinations of stem and affix; thus, *sportation is not a legal item in the sense that sport is 
a noun, but -ation can only add to verbs. Thus, Marelli and Baroni's comparisons of novel items are always legal combinations and their semantic interpretability is not a consequence of the validity of the morphological composition. Although *acneless is rated to be more meaningful than *hikeless, they are both legal combinations and look very similar on the surface.

There could be, however, a further cause for this difference, which may be due to hidden depths of morphological complexity. English is well known for zero-derivation or conversion, where nouns may become verbs and vice versa without any overt affixation: an eye vs. to eye, to run vs. a run (Bauer, Lieber \& Plag, 2013). Although on semantic grounds it may often be obvious which is the basic form (e.g. eye is a basic noun), this is not always the case. The word hike is equally plausible as a noun or a verb, but acne is clearly classified as a noun. For the suffix -less to attach to hike, it has to be the noun and not the verb. Is it possible that the morphological composition of *hikeless could be hike $e_{V E R B}>$ hike $_{\text {NOUN }}>$ *hikeless ${ }_{A D J E C T I V E}$ as compared to acne NOUN $>$ acneless $_{A D J E C T I V E}$ ? Even if the *hikeless derivation is directly from the noun hike, there is a difference in the morphological neighbourhood of hike and acne. Consequently, to what extent can the length of the derivational chain or morphological neighbourhood affect semantic interpretability? In fact, if morphological neighbourhood is a factor, then *hikeless would have more neighbours (both the noun and the verb) than *acneless. However, Marelli and Baroni's (2015) study was not concerned with derivational depth and morphological neighbourhood and it is not possible to discern to what extent some of the novel items were more complex than others.

The role of derivational depth, however, has been considered in other studies such as Meinzer, Lahiri, Flaisch, Hannemann and Eulitz (2009) and Pliatsikas, Wheeldon, Lahiri and Hansen (2014). Using fMRI, Meinzer et al. (2009) considered German derived nouns that looked equally complex in surface form, but differed in their internal morphological 
complexity. Words like Ebnung (N., 'flattening') were compared with words like Deutung (N., 'interpretation'); however, Ebnung has a two-step derivation through eben (A., 'flat') > ebnen (V., 'flatten') > Ebnung (N., 'flattening') while Deutung (N., 'interpretation') is onestep, deuten (V., 'interpret') > Deutung (N., 'interpretation') ${ }^{1}$. Increased LIFG activation was found for the more complex set as an index of processing effort. Following up on the German study, Pliatsikas et al. (2014) examined the difference between one- and two-step derived nouns, this time with zero-derivation in English. Words like bridging through bridge $_{\text {NOUN }}>$ bridge $_{V E R B}>$ bridging were compared with soaking ( $\operatorname{soak}_{V E R B}>$ soaking), both of which look very similar in terms of their surface morphological make-up, but differ in morphological complexity. In English, the suffix -ing can only be added to verbs, just as -less can only add to nouns (e.g. staying, bridging; but not, *graping from the noun grape or *happying from the adjective happy). Not only was the LIFG activation for complex words significantly higher than for the monomorphemic control verbs, but activation in two-step derived -ing forms was also significantly higher than in the less complex -ing forms (one-step). That is, the bridging set showed higher activation than the soaking set.

Combining the notion of semantic interpretability and morphological complexity, we turn to a comparison of novel items in German, which are semantically plausible, but morphologically deviant in different ways. For instance, novel items ending in the same suffix like *Spitzung (derived from spitz A., 'sharp') and *Hübschung (derived from hübsch A., 'pretty') differ because within the same derivational chain, there are differences where lexical gaps occur. Recall that nouns in -ung can only be derived from a verb, not directly from an adjective. However, although spitzen (V, 'to sharpen') exists, *hübschen does not; this means that a possible derivational chain of the novel item *Hübschung would have been hübsch $>$ *hübschen $>*$ Hübschung while that of *Spitzung is spitz $>$ spitzen $>*$ Spitzung.

\footnotetext{
${ }^{1}$ Note that German verbs will be cited with the infinitival ending -en. Thus, when verbs are zero-derived from an adjective, the verbs retains the ending -en to mark the infinitive.
} 
We thus find differences in the lexical composition within the same derivational chain adjective $>$ zero-derived verb $>$ noun ending in -ung. Sequences of multiple derivations - or simply, derivational chains - are also a common occurrence in English, with lexical gaps. To clarify, we provide an example. The word characterization has the derivational chain of character $_{N O U N}>$ character-ize $_{V E R B}>$ characterize-ation $_{\text {NOUN. }}$. Legal pseudowords can be made with these suffixes such as *criticization and *nationisation. However, these differ in intervening lexical gaps: critic $>$ criticize $>*^{*}$ criticization versus nation $>*^{*}$ nationize $>$ *nationization. These are exactly parallel to the German examples above. Our central question concerns how speakers treat these semantically plausible and morphologically viable pseudowords that constitute lexical gaps in derivational chains.

In the present study, our concern is thus with novel forms differing in intermediate stages of their derivation. We suspect that this might also contribute to how easy it is to integrate a novel form. Our prediction is that even though novel forms containing lexical gaps in their intermediate derivations can be decomposed, pseudowords in intermediate derivations might entail processing costs. This hypothesis is supported by the observation that even though we find complex words in language use that are derived from pseudowords in intermediate positions (indefatigable in English that is built on the pseudoword *defatigable through fatigable $>*$ defatigable $>$ indefatigable; cf. Booij, 2012, p.57), these formations are not very frequent on the whole.

Before addressing these issues empirically, we need to clarify the notion of 'derivational gap' that will be used in the present study. In theoretical linguistics, morphemeversus lexeme-based approaches make conflicting predictions regarding the participation of items in derivational processes that are not actual words. To illustrate this point, in English word-formation, we find words like navig-able in which the stem navig- as such is not an actual word. Under a lexeme-based approach, this issue does not arise because all elements 
that participate in word-formation are actual words, but this comes at the expense of having to include truncation to the list of word-building processes, e.g. navigate $>$ navigate -able $>$ navig-able. Under this analysis, -ate is truncated in the derivation of navigable. Morphemebased approaches more straightforwardly derive navigate from the nonword stem navig-. Similar issues were addressed experimentally by Taft and Forster (1975), who showed that the morpheme $d e$-could be stripped in forms like *dejuvenate although the stem juvenate was not an actual word. It was argued that nonword stems such as juvenate were directly listed in the lexicon, providing evidence for morpheme-based decomposition processes that are not reliant on existing lexical representations for the stems.

Our focus in the present paper is not on the decomposition of complex real words built on non-existing stems as 'derivational gaps', but rather on processing differences of pseudowords built with real stems. Both research questions are concerned with the internal composition of complex items that can only become available following decomposition. In the present study the two sets of pseudowords differ in the number of missing intermediate steps, as discussed above for *criticization and *nationisation. The novelty of our study thus lies in the empirical investigation of 'derivational gaps' at intermediate stages of morphological composition. Four experiments were designed to investigate the processing of meaningful pseudowords that include lexical gaps in their derivational chain: three lexical decision tasks with delayed priming and one regular lexical decision task. 


\section{Decomposing across lexical gaps in delayed priming: Experiments 1 and 2}

Empirical investigations of pseudowords within morphological processing have mainly focused on single-suffixed items (e.g. Longtin \& Meunier, 2005; Marelli \& Baroni, 2015). The study of more complex derived forms has restricted itself to real words in neuroimaging and in the modelling literature (e.g. Meinzer et al., 2009; Plag \& Baayen, 2009). In Experiments 1 and 2, we therefore first need to establish whether multi-affixed pseudowords can be decomposed to their base word lying two derivational steps away.

A number of different priming procedures such as masked priming, cross-modal repetition priming and delayed (also commonly termed 'long-lag') priming have been employed to understand whether morphologically complex words activate a morphologically related word. Across methodologies, it has been shown that the time course of activation differs between purely semantically related words (e.g. idea-notion), phonologically related pairs (e.g. brothel - broth) and morphological relatives (e.g. happiness - happy). As already discussed on the basis of the results obtained by Longtin and Meunier (2005) versus Meunier and Longtin (2007), semantic relatedness and interpretability did not modulate early stages of processing that can be tapped into using masked priming, but became evident in a crossmodal priming experiment. However, as structurally impossible combinations (e.g. *sportation in Longtin \& Meunier, 2005) also showed evidence of decomposition in masked priming, masked priming does not lend itself to the study of morphological viability for our set of experiments. In cross-modal priming, on the other hand, where the target is presented immediately after the prime, priming effects between semantically related words without a morphological relationship, such as idea and notion, have been reported (Marslen-Wilson, Tyler, Waksler, \& Older, 1994). This exacerbates the dissociation of morphological from semantic effects since morphologically related words are commonly also related in meaning. Our interest in the present study, however, is in purely morphological effects. In so-called 
delayed (or long-lag) priming paradigms, purely semantic effects have been shown to dissipate while priming between morphologically related words is preserved in the absence of any orthographic or phonological effects (Marslen-Wilson \& Tyler, 1998; Henderson, Wallis, \& Knight, 1984; Drews \& Zwitserlood, 1995; Bozic, Marslen-Wilson, Stamatakis, Davis, \& Tyler, 2007; Scharinger, Reetz, \& Lahiri, 2009; Lahiri \& Reetz, 2010; Bentin \& Feldman, 1990; Napps \& Fowler, 1987; Marslen-Wilson, 2007). This dissociation is achieved through a delay in the presentation of the target following its associated prime; either through the selection of a long ISI or through the insertion of intervening stimuli between prime and target. The number of intervening stimuli has been found to vary across delayed priming experiments, but the absence of facilitatory effects for purely semantically related words has been consistent. While delayed priming effects have been argued to be the result of both abstract and episodic effects with purely episodic effects decreasing at longer lags, Kouider and Dupoux (2009) demonstrate that abstract effects such as morphological priming remain robust and constant across different lags in delayed priming. Feldman and Moskovljevic (1987) also show that for shorter lags, episodic effects cannot account for morphological facilitation as priming effects persist across changes in alphabetic script.

We included 5-7 intervening items between prime and target based on a previous study that contrasted cross-modal priming and delayed priming directly and only found semantic effects in the former (Scharinger et al., 2009). Two lexical decision tasks with delayed priming were carried out, comparing the processing of *Spitzung (Experiment 1 ) and *Hübschung (Experiment 2) with that of existing two-step derived nouns like Heilung (N., 'healing'). In this part of the study, it was decided to keep the two sets separate across the two experiments to avoid the influence of one on the other. As speakers give lexical decisions to both primes and targets in delayed priming, it will also be possible to probe into the processing of the two sets of morphologically viable pseudowords in comparison with non- 
complex pseudoword fillers through the analysis of responses to the primes. The two delayed priming experiments differed in one test condition. In Experiment 1, we investigated whether complex pseudowords that are one derivation away from a lexical representation (e.g. *Spitzung through spitz $>$ spitzen $>{ }^{*}$ Spitzung) could be decomposed. In this condition (hereafter called 'NonEx1'), items have the features \{+ Morphologically complex; - Extant noun; + Extant intermediate derivation $\}$. In Experiment 2, we increased the number of derivations that proceed without the support of a lexical representation by looking into the decomposition of forms like *Hübschung for which the complex verb *hübschen filling the intermediate derivational position does not exist, giving this condition ('NonEx2') the features $\{+$ Morphologically complex; - Extant noun; - Extant intermediate derivation $\}$. An example for each type of test item used in Experiment 1 is given in Table 1.

\section{Insert Table 1 about here}

In Experiment 2, we kept the test condition 'Extant' for which all stages of the derivation are filled with lexical representations. Condition 2 was replaced with items like *Hübschung that display the features $\{+$ Morphologically complex; - Extant noun; - Extant intermediate derivation $\}$. Table 2 gives an overview of the test conditions in Experiment 2.

\section{Insert Table 2 about here}




\section{Experiment 1: Decomposition of two-suffixed pseudowords}

Method

\section{Materials Experiment 1}

There are two conditions in this experiment: condition 'Extant' containing real complex nouns (e.g. Heilung (N., 'healing')) and condition 'NonEx1' containing pseudonouns (e.g. *Spitzung (N., 'sharpening')) derived on the basis of the same derivational chain as 'Extant'. In both conditions, target items comprise 16 extant adjective and 16 extant verb base forms. In the 'Extant' condition, all forms within the derivational paradigm exist. Items in the 'NonEx1' condition follow the same derivational chain as in 'Extant' (base adjective $>$ zeroderived verb $>$ noun in - ung or verb $>$ adjective in - bar $>$ noun in -keit), but the final noun form does not exist. In an off-line rating task with a student population of German native speakers, only items in condition 'Extant' were judged to be existing words in German. In both conditions, unrelated control primes consist of morphologically complex forms built using bases that are matched on critical factors such as lexicality, full form and base frequency, length and syllable structure. The full form is either extant ('Extant') or nonexistent ('NonEx1'). For each condition, an example of the derivational paradigm for both adjectival and verbal bases is given in Table 3 .

\section{Insert Table 3 about here}

Prime items in all test conditions that are built on adjectives as roots are disyllabic with wordinitial stress. Verb-based noun primes are a syllable longer and stress also falls on the first syllable. T-tests between the two conditions showed no significant differences in target word 
length, target word frequency, target lemma frequency, prime-target overlap, orthographic family size of the target, phonological size of the target and morphological family size between conditions. Within each condition, related and unrelated primes were matched in length, lexical status, frequency, syllable structure and stress (see Appendix).

\section{Fillers}

In order to obfuscate the relationship of interest between words, 32 semantically related pairs (16 adjective-based; 16 verb-based) such as Schnelle (N., 'rapidness') and fix (A., 'quick'), as well as two sets of 32 phonologically related pairs were included. In order to provide a balanced design in the number of word and nonword stimuli presented to the participants, 96 further pairs of 'nonword' prime and 'nonword' target pairs, as well as a set of 64 'word' prime and 'nonword' target pairs were included. The total number of items was 640 per list.

\section{Participants}

38 German native speakers participated in Experiment 1, of whom 23 were female. All subjects were students at the Goethe University in Frankfurt and were native speakers of Standard German. The study was approved by the local research ethics committee. Each participant gave their informed consent for participation and was reimbursed appropriately (10€/hour).

\section{Procedure}

The experiment took place in a quiet room at the Goethe University in Frankfurt. The experimental environment consisted of the experimental hardware, a MacBook Pro running OS X from which the XMOD data gathering software (Reetz \& Kleinmann, 2003) was operated, push button boxes to give and record responses, and a video projector to present the 
stimuli on a screen. Each stimulus was presented in upper case ${ }^{2}$ and remained on the projector screen for $500 \mathrm{msec}$. Participants had up to $2500 \mathrm{msec}$ to make a lexical decision. Two experimental lists were employed, in which the presentation of stimuli was pseudorandomised. Participants were assigned to one of the two experimental lists and only saw each target once preceded by either its related or unrelated prime. The presentation of related versus unrelated primes in test conditions was counterbalanced across the two lists. Primes and targets were separated by 5 to 7 intervening items. Before starting the experiment, test subjects participated in a test run consisting of 10 practice items. Participants were instructed to respond to every item on the screen by deciding whether it was an extant word in German or not, using the push button box provided. 'YES' responses were made by the participant's dominant thumb.

\section{Results}

Target analysis. Two participants with error rates higher than 2 standard deviations from the mean $(\sim 5.3 \%$ excluded of total data $)$ and the item wett $(\sim 1.5 \%$ excluded $)$ that elicited high error rates across all participants were excluded. Items for which reaction times exceeded the participant's individual cut-off point of $+/-2$ SD their mean reaction time to targets were not included in the analysis $(\sim 1.7 \%)$. Only correctly classified targets in the test conditions were submitted to further data analysis $(\sim 1.9 \%$ excluded). The overall amount of data excluded across conditions did not differ $(\mathrm{p}>.54)$.

Reaction times were log-transformed in all analyses. Based on these data, a two-factor linear mixed model analysis was performed, using the fixed factors Prime Type (Related versus Unrelated) and Base (Ex versus NonEx1) and the random factors Subject and Item for the log-transformed reaction times in the statistical package $R$ and its downloadable package

\footnotetext{
${ }^{2}$ All items were displayed in block capitals: this was considered the most neutral way to present experimental stimuli in German, since German nouns are commonly capitalised in line with orthographic conventions.
} 
lme4 for mixed effects modelling. Contrasts for our fixed effects were sum-coded using $(-1 / 1)$ coding and random slopes were included when their inclusion resulted in a significantly better fit of the model to our data as accessed through a likelihood ratio test (Bates, Kliegl, Vasishth, \& Baayen, 2015). A model containing random intercepts for Subject and Item and by-item random slopes for Prime Type provided the best fit for our data. Through model comparison with and without the relevant fixed factor, we found a significant main effect of Prime Type $\left(\chi^{2}(1)=10.448, \mathrm{p}=.001\right)$ with no other main effects or interactions reaching significance. This means that a priming effect in delayed priming could be established for both real words and possible pseudowords like *Spitzung (see Figure 1). Error bars represent the standard error in all figures.

\section{Insert Figure 1 about here}

Prime analysis. Given that primes are on average a syllable longer than target items in this study, it was deemed worthwhile to calculate mean reaction times to primes only and to exclude all reaction times falling +/- 2 SD from a participant's mean reaction time to primes. Moreover, items that are non-existent, but contain no morphological structure were included in this part of the analysis in a condition termed 'Control NonEx'. Adjective-based controls were built on the basis of matched adjectives to which a pseudosuffix such as -ang was attached (e.g. *Plümpang based on plump). Verb-based controls were built on the basis of a matched verb stem that was followed by a sequence of two suffixes the combination of which is not morphological. The combination employed violates morphotactic constraints given that nominalisation suffixes such as -nis do not attach to adjectives that are already suffixed 
(Fleischer, 1975). Similarly, pseudo-suffixes such as -mut do not follow adjectives that are already suffixed. Noncomplex controls for the 'Non-Ex1' condition are matched in frequency of the 'base word', word-length, syllable-structure and stress pattern with the corresponding complex items in 'Non-Ex1'. In the reaction time analysis to these test primes, only correctly classified items in the three categories 'Extant', 'Control NonEx' and 'NonEx1' were submitted to data analysis. Mean reaction times for the lexical decision task to primes are shown in Figure 2.

\section{Insert Figure 2 about here}

To investigate the effect of Base on Reaction time, a linear mixed model analysis with the fixed factor Base and the random factors Subject and Item was performed using the statistical analysis software $R$ and its downloadable package lme4. A linear mixed model with random intercepts for Subjects and Items and random slopes for Subjects provided the best model fit. In this model, the fixed effect Base affected Reaction time $\left(\chi^{2}(2)=36.511, \mathrm{p}<.0001\right)$. We established pairwise comparisons between all conditions using the $\mathrm{R}$ package lsmeans. All pairwise comparisons were significant at $\mathrm{p}<.01$ (Control NonEx versus Extant: Est. = $0.03914, \mathrm{SE}=0.01247, \mathrm{t}(79)=3.139, \mathrm{p}<.01 ;$ Control NonEx versus NonEx1:

Est. $=-0.04768, \mathrm{SE}=0.01364, \mathrm{t}(79)=-3.495, \mathrm{p}<.01 ;$ Extant versus NonEx1: Est. $=-0.08681, \mathrm{SE}=0.01309, \mathrm{t}(79)=-6.634, \mathrm{p}<.001)$. Crucially, participants were significantly slower at classifying 'NonEx1' items such as *Spitzung than their non-complex controls like *Plümpang, suggesting that the structural validity of constructions such as *Spitzung was instantiating a delay in lexical decision times. In the error rate analysis the same criteria for 
exclusion of participants or individual data points were followed, with the difference that both correctly and incorrectly classified items were submitted to data analysis. Error rates for the three categories 'Extant', 'Control NonEx' and 'NonEx1' are given in Figure 3.

\section{Insert Figure 3 about here}

The data were analysed using a binomial generalised linear model (GLM) with Base as fixed factor and Error rate as dependent variable. Base significantly improved the fit of the model, $\chi^{2}(2)=672.72, p<.0001$. Planned pairwise comparisons showed that the *Spitzung set differed from the other two sets at $p<.001$. (Extant versus Control NonEx: Est. $=0.2334, \mathrm{SE}$ $=0.2668, \mathrm{z}=0.875, \mathrm{p}=0.651$; Extant versus NonEx1: Est. $=3.6063, \mathrm{SE}=0.2178, \mathrm{z}=$ 16.559, $\mathrm{p}<.001$; Control NonEx versus NonEx1: Est. $=3.3729, \mathrm{SE}=0.2019, \mathrm{z}=16.706, \mathrm{p}$ $<.001)$. As in the prime reaction time analysis, complex pseudowords such as *Spitzung were found to produce the most difficulty in classification, eliciting by far the highest error rates.

\section{Discussion}

In Experiment 1, priming effects were observed between extant morphologically complex words and their base words (e.g. Heilung and heil), as well as for pairs in which the final noun form is not listed (e.g. *Spitzung and spitz). When considered in conjunction with previous studies on the processing of complex pseudowords, this implies that the application of morphological decomposition is not restricted to single-suffixed pseudowords. Morphologically possible pseudowords such as *Spitzung also elicited significantly longer 
lexical decision times and higher error rates than matched non-complex control nonwords. The morphological validity of the internal structure in pseudowords such as *Spitzung thus has an effect on the processing of novel forms. In order to elucidate the internal composition of the derivational chain further, we conducted Experiment 2 in which the intermediate position is a lexical gap.

\section{Experiment 2: Decomposing through lexical gaps}

In Experiment 1, we saw that morphologically possible pseudowords activated their respective base word that is two derivations away. In a next step, we decided to manipulate the internal composition of possible pseudowords such as *Hübschung in Experiment 2. For this purpose, we investigated the processing of complex pseudowords for which the intermediate derivation contains a lexical gap.

Method

\section{Materials Experiment 2}

As none of the subjects in Experiment 2 had participated in the previous experiment, the same stimuli for the condition 'Extant' (see Table 3) were employed in this part of the study. Condition 'NonEx2' is composed of complex pseudowords for which the nearest extant representation is a two-step derivation away. Thus, the possible pseudonoun *Hübschung is built according to the derivational pattern hübsch $>$ *hübschen $>*$ Hübschung. These nouns appear as primes in the experiment and are paired with their extant base forms as targets. All targets in the present 'NonEx2' condition were matched on word and lemma frequency, word length, prime-target overlap, phonological, orthographic and morphological family size, as 
well as syllable structure with 'NonEx1' and all other stimuli that appear in this series of experiments.

\section{Participants}

32 German native speakers volunteered to participate in Experiment 2, of whom 22 were female. None of the participants from Experiment 1 took part in this follow-up experiment. All participants gave their informed consent for participation and were reimbursed appropriately for their time (10€/hour).

\section{Procedure}

The methodology for this experiment was identical to Experiment 1.

\section{Results}

Target analysis. The same criteria for filtering the data as in Experiment 1 were applied in Experiment 2, resulting in the exclusion of two participants with high error rates $(\sim 6.25 \%$ excluded). Only responses within two standard deviations of a participant's mean reaction time to targets were included $(\sim 2.8 \%$ excluded $)$. Incorrect responses $(\sim 2.2 \%)$ were not included. The overall amount of data excluded across conditions did not differ $(p>.97)$. Figure 4 shows a plot of reaction times for targets in both conditions following related and unrelated primes.

\section{Insert Figure 4 about here}


Model construction on the log-transformed reaction times followed the same procedure as in Experiment 1. In a model containing the fixed factors Prime Type (Related versus Unrelated) and Base (Ex versus NonEx2), random intercepts for Subject and Item and by-item random slopes for Prime Type, we found a significant main effect of Prime Type $\left(\chi^{2}(1)=22.75, \mathrm{p}<\right.$ .0001) with no other main effects or interactions reaching significance. The priming effect reported in Experiment 1 for the 'Extant' items could be replicated. Moreover, presentation with morphologically possible pseudowords such as *Hübschung that are two derivations away from an extant lexical representation also facilitated lexical decisions to their base forms (here hübsch). Possible pseudowords could thus be decomposed across lexical gaps for intermediate positions within the derivational chain.

Prime analysis. The same procedures for data filtering as Experiment 1 were applied. Mean reaction times to all conditions of interest are given in Figure 5.

\section{Insert Figure 5 about here}

A linear mixed model analysis was performed with the fixed factor Base and the random factors Subject and Item. Through step-wise simplification of the maximal random structure, we found a linear mixed model with random intercepts for Subjects and Items to provide the best model fit. Base affected Reaction time $\left(\chi^{2}(2)=54.584, p<.0001\right)$. Pairwise comparisons were established between all conditions using the R package lsmeans. Again, all pairwise comparisons were significant at $\mathrm{p}<.01$ (Control NonEx versus Extant: Est. = 0.05435, $\mathrm{SE}=0.01234, \mathrm{t}(75)=4.406, \mathrm{p}<.001$; Control NonEx versus NonEx: Est. $=-$ 
0.04123, $\mathrm{SE}=0.01291, \mathrm{t}(75)=-3.194, \mathrm{p}<.01 ;$ Extant versus NonEx: Est. $=-0.09558, \mathrm{SE}$ $=0.01108, \mathrm{t}(75)=-8.624, \mathrm{p}<.001)$. As in Experiment 1, there were significant differences between the two sets of nonwords. Morphologically possible pseudowords such as *Hübschung elicited significantly longer reaction times than their non-complex controls like *Plümpang. $\quad$ In the error rate analysis, the data were trimmed on the basis of the same criteria as for the reaction time analysis, but with both correct and incorrectly classified items entering data analysis. Figure 6 gives an overview of error rates for the three categories of interest in this part of the study ('Extant' versus 'Control NonEx' versus 'NonEx2').

\section{Insert Figure 6 about here}

In a binomial generalised linear model, the factor Base had a significant effect on Error rate, $\chi^{2}(2)=192.8831, \mathrm{p}<.0001$. Again, speakers made significantly more errors when attempting to classify morphologically possible pseudowords such as *Hübschung than when presented with morphologically impossible items (e.g. *Plümpang), Est. $=1.9377, \mathrm{SE}=$ $0.1917, \mathrm{z}=10.110, \mathrm{p}<.0001$ or with extant (e.g. Heilung) words, Est. $=2.1436, \mathrm{SE}=$ $0.1998, \mathrm{z}=10.727, \mathrm{p}<.0001$.

\section{Interim discussion and follow-up issues}

The results obtained in Experiments 1 and 2 suggest that a complex form can contain lexical gaps within its derivational chain and still activate a base word that is multiple derivational steps away. On the one hand, this could mean that processing of morphological complexity can proceed 'on-line' and is not reliant on stored lexical representation within the derivational 
paradigm. On the other hand, it is clear that morphologically complex words and pseudowords share a high degree of semantic and formal overlap with their respective base forms. It is thus also possible that the priming effect we have observed in Experiments 1 and 2 was driven by the semantic or formal relationship between prime and target. In order to be able to differentiate between these two options, Experiment 3 was conducted in which we included purely semantically and phonologically related control items. Moreover, given our research focus on the role of lexical gaps in derivational paradigms, it was decided that a more direct comparison of the priming effects seen for the two types of morphologically viable pseudowords (*Spitzung and *Hübschung) should be established. Experiments 1 and 2 provided evidence that decomposition of multi-suffixed pseudowords was possible and that this form of decomposition could span a series of derivations. Experiments 3 and 4 will allow a more direct comparison of the decomposition and processing of multi-suffixed complex items that contain lexical gaps in different parts of their derivational chain (spitz $>$ spitzen $>$ *Spitzung versus hübsch > *hübschen $>$ *Hübschung).

\section{Experiments 3 and 4: Investigating degrees of morphological violation}

If knowledge of morphological viability plays a role in word recognition, then relative degrees of morphological viability should also be discernible. Recall that in morphological theory, there is a long-standing debate regarding the validity of word-formation rules that operate on possible, but not actual words. Thus, while both *Spitzung and *Hübschung are formed following viable morphological rules of German word-formation, *Spitzung should be felt to be a more probable possible word than *Hübschung if word-formation rules only operate on actual words. To investigate this hypothesis, a more direct comparison between the *Spitzung and *Hübschung cases was carried out in Experiments 3 and 4. Experiment 3 is 
a lexical decision task with delayed priming in which participants are presented with all the morphological conditions examined in Experiments 1 and 2. Moreover, semantically and phonologically related control pairs were included in Experiment 3. If we obtain no priming effects in the non-morphological conditions, we have further substantiation that delayed priming taps into purely morphological processing. An additional simple lexical decision task to primes only was carried out in Experiment 4, comparing the processing of 'NonEx1', 'NonEx2' and noncomplex items more directly after we found asymmetries in the processing of different types of nonwords in the previous two experiments.

\section{Method}

\section{Materials Experiment 3}

Experiment 3 is made up of six experimental conditions with 24 experimental items each. All three morphological conditions from Experiments 1 and 2 were included in this experiment, as well as semantically and phonologically related controls. These were selected in accordance with the following criteria:

(1) Form control for 'NonEx'; Base = Adjective: Form controls for the 'NonEx' condition comprise primes and targets that are matched for word frequency, lemma frequency, wordlength, morphological family size, orthographic family size, phonological family size, primetarget overlap, syllable-structure and stress pattern with the corresponding test items in the 'NonEx' categories (see Appendix). 'Non-Ex'- control targets are built from an extant base word (e.g. steil) that is matched in lemma and word frequency, as well as word length, morphological family size, orthographic family size, phonological family size, prime-target overlap, syllable structure and stress pattern with the bases in the two 'NonEx' categories. Where appropriate, back stem vowels were fronted (i.e. umlauted) to ensure a maximum 
degree of purely visual overlap between 'NonEx' primes and their controls. Endings for control primes consist of suffixes such as -lein, -ler that require nominal, not adjectival bases and which are therefore not combinable with the relevant base form.

(2) Form control for 'NonEx'; Base = Verb: Control nouns for the 'NonEx' conditions were constructed by using a combination of two suffixes that are not morphotactically admissible. Targets are again matched for word and lemma frequency, word length, morphological family size, orthographic family size, phonological family size, syllable structure and stress pattern with the bases in the other experimental conditions. To give an example, the related prime *Schieblosler is based on the stem of the extant German verb schieben to which the two suffixes -los, -ler are added. The suffix -los, however, forms adjectives by attaching to nominal, not verbal bases. Moreover, -ler also requires a nominal, not an adjectival base. The item *Schieblosler should therefore not be decomposable.

(3) Form control for 'Extant'; Base = Adjective: Prime and target items display a high degree of visual overlap (including the application of umlauting where appropriate), but are not morphologically related. The prime Täublein (N., 'little pigeon'), for instance, is a complex morphological word that is morphologically related to Taube (N., 'pigeon'), but not to the adjective taub (A., 'deaf') as the corresponding target, which is again matched to the other conditions in this experiment.

(4) Form control for 'Extant'; Base = Verb: As in (3), matched form control pairs for 'Extant' that are verb-based display a high degree of visual similarity without being morphologically related to one another. Prime-target pairs in this condition (e.g. prime Daunenbett ('eiderdown') - target dauern ('to last')), have a visual overlap of at least three 
initial letters but even though the prime is an extant complex word, it is not morphologically related to the target with which it is paired.

(5) Semantic control for 'Extant'; Base = Adjective: Extant words like Schnelle (N., 'rapidness') and fix (A., 'quick') are related in meaning, but do not display a morphological relationship. Semantic relatedness was operationalized as follows: for every base word that is matched to the other conditions in this experiment, a synonym was selected. Subsequently, a noun was derived from this synonym that was used as the corresponding related prime. The unrelated prime was a semantically unrelated morphologically complex word. All related and unrelated primes and their targets were submitted to 40 native speakers of German who did not participate in any of the experiments for a semantic relatedness questionnaire. The participants in this questionnaire were asked to rate on a scale from 1 to 7 to what extent the meaning expressed by the paired words was synonymous $(1$ = entirely unrelated in meaning; 7 = same meaning, synonymous). Related pairs had an average relatedness rating of 4.43, unrelated pairs received an average rating of 1.57.

(6) Semantic control for 'Extant'; Base = Verb: Like in (5), extant words like Reinigung $(\mathrm{N}$, 'cleaning') and putzen (V, 'to clean') are meaning-related, but share no form overlap and are not morphologically related to one another. Semantic relatedness was determined as in (5).

Tables 7 and 8 (in the appendix) give examples of the stimuli employed for each condition, as well as statistical support for the matching of stimulus properties. Stimuli were matched on target length, target word frequency, target lemma frequency, orthographic, phonological and morphological family size across conditions (no significant differences for all criteria). All 
morphological conditions and the non-existent control condition were also matched on primetarget overlap. Related versus unrelated primes were matched on prime length, word and lemma frequency. Frequency information, as well as measures of morphological family size was obtained using the CELEX simplex interface (http://web.phonetik.unifrankfurt.de/simplex.html). Morphological family size was operationalized as the number of semantically transparent morphologically related words extracted from CELEX for a given base. Orthographic and phonological neighbourhood sizes were retrieved using Clearpond (Marian, Bartolotti, Chabal, \& Shook, 2012; http://clearpond.northwestern.edu).

\section{Participants}

34 German native speakers who were all students at Goethe University, Frankfurt volunteered to participate in Experiment 3. None of the participants from Experiments 1 and 2 took part in this follow-up experiment. All participants gave their informed consent and were reimbursed appropriately for their time (10 €/hour).

\section{Procedure}

The methodology for this experiment was identical to Experiments 1 and 2. As in Experiments 1 and 2, a lag of 5-7 intervening stimuli was selected. Each group was presented with 576 items in total.

\section{Results}

Two items were excluded due to a coding error and three items (zollen, weisen and ahnden) were excluded due to high error rates ( $>25 \%$ resulting in exclusion of $3.5 \%$ of total data). 
Only responses that lay within 2 SDs of the participant's mean reaction time to targets $(1.3 \%$ excluded) and only correct responses were included ( $2.7 \%$ of total data excluded). There were no statistically significant differences in the amount of data excluded across conditions. Mean reaction times (with standard deviations) and error rates by condition are given in Table 4.

\section{Insert Table 4 about here}

The same procedure for target analysis was applied as in Experiments 1 and 2. Reaction times were log-transformed. In a linear mixed model with Prime Type (Related versus Unrelated) and Base (Extant, NonEx1, NonEx2, Control NonEx, Form Control Extant, Semantic) as fixed effects, Subject and Item as random effects (with intercepts only as adding random slopes did not significantly improve model fit), we found that Prime Type affected reaction times at $\left(\chi^{2}(1)=26.807, \mathrm{p}<.0001\right)$ and Base was significant at $\left(\chi^{2}(5)=11.143, \mathrm{p}<\right.$ .05). The interaction between the factors Prime Type and Base reached significance at $\left(\chi^{2}(5)\right.$ $=21.236, \mathrm{p}<.001)$.

In view of the significant interaction between Prime Type and Base, pairwise comparisons for the priming effect were carried out in all six experimental conditions using lsmeans. Results of Tukey-adjusted pairwise comparisons between the Related and Unrelated sets showed significant priming only in the morphological conditions (Form Control Extant: Est. $=0.001505, \mathrm{SE}=0.005120, \mathrm{t}(4304)=0.294, \mathrm{p}=.769 ;$ Control NonEx:

Est. $=-0.008132, \mathrm{SE}=0.005284, \mathrm{t}(4304)=-1.539, \mathrm{p}=.124 ;$ Extant:

Est. $=-0.018217, \mathrm{SE}=0.004873, \mathrm{t}(4303)=-3.738, \mathrm{p}<.001 ;$ NonEx1: Est. $=-0.025851$, 
$\mathrm{SE}=0.004985, \mathrm{t}(4303)=-5.186, \mathrm{p}<.0001 ;$ NonEx2: Est. $=-0.010895, \mathrm{SE}=0.004923$, $\mathrm{t}(4304)=-2.213, \mathrm{p}=.0269 ;$ Sem: Est. $=-0.001363, \mathrm{SE}=0.004822, \mathrm{t}(4303)=-0.283$, $\mathrm{p}=.777)$. P-values were obtained using Satterthwaite approximations for the computation of our degrees of freedom. In Experiment 3, we have priming only in the morphological conditions. The priming effects observed in the present experiment can therefore not be reduced to purely semantic or formal overlap between prime and target. We then conducted a follow-up analysis for the two pseudoword conditions only. In this analysis, we found a significant effect of Prime Type $\left(\chi^{2}(1)=26.738, \mathrm{p}<.0001\right)$, as well as a significant interaction between Prime Type and Base $\left(\chi^{2}(1)=4.6029, \mathrm{p}<.05\right)$. Possible pseudowords that are derived from an actual word within the intermediate position, such as *Spitzung, primed their base more strongly than pseudowords derived from a non-existing word in the intermediate position of the derivational chain such as *Hübschung (see Figure 7).

\section{Insert Figure 7 about here}

Prime analysis. In line with the analyses for Experiments 1 and 2, we also conducted a reaction time and error rate analysis to primes in Experiment 3. We followed the same procedure as in Experiments 1 and 2 for data filtering and model construction. Mean reaction times and error rates to primes can be found in Table 5 .

\section{Insert Table 5 about here}


In a linear mixed effects model with Base as fixed effect and Subject and Item as random effects with random intercepts, we found a significant effect of Base on Reaction time ( $\chi^{2}(3)$ $=70.452, \mathrm{p}<.0001)$. This effect was, however, solely driven by the lexical status of the item. Unlike the results in Experiments 1 and 2, we found no differences in reaction time between the three sets of pseudowords. In the error rate analysis, however, Base had a significant effect on Error rate, $\chi^{2}(3)=380.587, \mathrm{p}<.0001$. In this analysis, we found significant differences between all the pseudoword conditions (Extant versus NonEx1: Est. $=3.7334, \mathrm{SE}$ $=0.2853, \mathrm{z}=13.087, \mathrm{p}<.0001 ;$ Extant versus NonEx2: Est. $=2.4390, \mathrm{SE}=0.2870, \mathrm{z}=$ 8.499, $\mathrm{p}<.0001$; Control NonEx versus NonEx1: Est. $=2.3183, \mathrm{SE}=0.1881, \mathrm{z}=12.323, \mathrm{p}<$ .0001 ; Control NonEx versus NonEx2: Est. $=1.0238, \mathrm{SE}=0.1907, \mathrm{z}=5.370, \mathrm{p}<.0001$; NonEx1 versus NonEx2: Est. $=-1.2944, \mathrm{SE}=0.1585, \mathrm{z}=-8.167, \mathrm{p}<.0001)$. As in the prime analysis for Experiments 1 and 2, pseudowords that are not morphologically viable (e.g. *Steillein) elicited the lowest error rates and could therefore be classified more accurately than pseudowords that possess internal morphological structure ( ${ }^{*}$ Spitzung and *Hübschung). Moreover, pseudowords like *Spitzung for which the intermediate position is an actual word had higher error rates than items from the Hübschung set for which the intermediate verb is a pseudoword *hübschen.

\section{Discussion}

In sum, when both types of pseudowords *Spitzung and *Hübschung are presented to participants in a single delayed priming experiment, differences in priming magnitude emerge. These differences are also discernible in the reactions to the complex items. Possible pseudowords that are derived from an actual word in the intermediate position such as *Spitzung elicit significantly higher error rates than morphologically possible pseudowords such as *Hübschung that are two derivations away from the nearest lexical representation 
within the derivational chain. Differences in reaction times to the complex pseudowords were not discernible. This is in line with the findings reported by Yap, Sibley, Balota, Ratcliff and Rueckl (2015) where the number of affixes in a nonword affected reaction times. Note that the number of affixes in the two pseudoword sets *Spitzung and *Hübschung is equal despite differences in lexical composition. However, as we found significant differences between the two sets in the error rate analysis, we considered whether this difference could have been driven by differences in familiarity between *Spitzung and *Hübschung. ${ }^{3}$ It is worth noting here the processing of morphologically viable Dutch neologisms such as *lobbigheid (N., 'softness') in a study by de Vaan, Schreuder and Baayen (2007) in a visual lexical decision task with long-lag priming (39 intervening items). The participants were instructed to respond "yes" to neologisms if they seemed like words. It was observed that that these pseudoword primes led to identity priming only when they were classified as possible words, showing that novel forms can leave memory traces after a single presentation. In view of this study, we also assessed the influence of the pseudoword prime if it was responded to as a word. That is, would priming occur only if *Spitzung or *Hübschung were responded to as words? For this purpose, we included the predictor variable Prime classification in our model in addition to the factors Prime Type and Base. As in the previous model, only the main effect of Prime Type $(\mathrm{p}<.0001)$ and the interaction between Prime Type and Base $(\mathrm{p}<.05)$ reached significance. Neither the main effect of Prime classification nor any interactions with the factors Prime Type and Base showed a significant effect on reaction times. The priming effect was thus independent of the classification of the prime, demonstrating that possible differences in familiarity with the novel form cannot account for priming differences.

\footnotetext{
3 *Spitzung, for instance, though not in use today, is a technical term attested in the 1930 s to designate the pointing of fox fur.
} 


\section{Experiment 4: The role of the lexical representation in derivational paradigms during processing of morphological complexity}

In all experiments so far, complex items and their noncomplex controls were paired with their corresponding targets. In this final experiment, we decided to run a simple lexical decision task to primes only as this might accentuate the difference in processing between the sets of complex items and their controls. Moreover, as the *Plümpang set has not yet been directly compared with both types of morphologically possible pseudowords (*Spitzung and *Hübschung), Experiment 4 was carried out in order to contrast this type of nonmorphological control with the two sets of possible pseudowords.

\section{Method}

\section{Materials Experiment 4}

Only the stimuli that constitute primes in the conditions 'Extant', 'Control NonEx', 'NonEx1' and 'NonEx2' (32 words per condition) in Experiments 1 and 2, i.e. complex extant and non-existent nouns, as well as their control forms (e.g. *Plümpang) appear in this experiment. Recall that these were controlled for word and lemma frequency, length, stress patterns, morphological, phonological and orthographic family size (see Experiments 1 and 2). 128 filler words were included to match the total number of words and nonwords in the experiment and to avoid any possibility of a bias. These filler words also had the appearance of morphologically complex items. Participants saw 256 items in total.

\section{Participants}

A group of 20 native speakers of German who were students at the Goethe University, Frankfurt participated in the simple lexical decision task, none of whom had taken part in any 
of the previous studies. Participants gave their informed consent and were reimbursed appropriately.

\section{Procedure}

The same procedure was applied as in the previous three experiments. All participants were presented with the same pseudorandomised experimental list.

\section{Results}

One participant had to be excluded as they had misunderstood the task instructions. As in previous experiments, items for which reaction times exceeded two standard deviations below or above the mean were considered outliers and not included in the subsequent data analysis. For the first part of the analysis that focused on reaction times, only correctly identified items entered the statistical data analysis. In the error analysis, both correct and incorrect responses entered data analysis.

\section{Reaction time analysis.}

Mean reaction times to all primes are given in Table 6.

\section{Insert Table 6 about here}

In a linear mixed model analysis with random intercepts for Subjects and Items and bysubject slopes, the effect of Base ('Extant', 'NonEx1', 'NonEx2' and 'Control NonEx') on Reaction Time was investigated. The fixed effect Base had a significant effect on Reaction time $\left(\chi^{2}(3)=36.713, \mathrm{p}<.0001\right)$. All pairwise comparisons between the 'Extant' condition 
and the different types of pseudowords reached significance at $p<.01$ with extant words being identified faster (Extant versus Control NonEx: Est. $=-0.050386, \mathrm{SE}=0.013687, \mathrm{t}(71)$ $=-3.681, \mathrm{p}<.01 ;$ Extant versus NonEx1: Est. $=-0.092181, \mathrm{SE}=0.013668, \mathrm{t}(71)=-6.744, \mathrm{p}$ $<.001$; Extant versus NonEx2: Est. $=-0.083746, \mathrm{SE}=0.011536, \mathrm{t}(71)=-7.259, \mathrm{p}<.001)$. As already seen in Experiments 1 and 2, 'Control NonEx' items were also rejected significantly faster than both sets of possible pseudowords (Control NonEx versus NonEx1: Est. $=-0.041795, \mathrm{SE}=0.014352, \mathrm{t}(71)=-2.912, \mathrm{p}<.05 ;$ Control NonEx versus NonEx2: Est. $=-0.03336, \mathrm{SE}=0.012144, \mathrm{t}(71)=-2.747, \mathrm{p}<.05)$. No significant difference emerged in the comparison of reaction times to items in 'NonEx1' versus 'NonEx2'.

\section{Error analysis.}

Figure 8 gives an overview of error rates for the four categories of interest in this part of the study ('Extant' versus 'Control NonEx' versus 'NonEx1' versus 'NonEx2').

\section{Insert Figure 8 about here}

A generalised linear model (GLM) was performed in order to analyse the effect of Base on Error rate. The effect was significant at $\chi^{2}(3)=610.6585, \mathrm{p}<.0001$. Pairwise comparisons using lsmeans were conducted to inspect differences between experimental conditions. All comparisons apart from the comparison between 'Extant' (Heilung) and the 'Control NonEx'

(*Plümpang) category showed a significant difference at $\mathrm{p}<.0001$. (Extant versus NonEx1: Est. $=3.2215, \mathrm{SE}=0.1939, \mathrm{z}=16.616, \mathrm{p}<.0001$; Extant versus NonEx2: Est. $=1.4477, \mathrm{SE}$ $=0.2025, \mathrm{z}=7.148, \mathrm{p}<.0001 ;$ Control NonEx versus NonEx1: Est. $=3.9659, \mathrm{SE}=0.3487, \mathrm{z}$ 
$=11.372, \mathrm{p}<.0001$; Control NonEx versus NonEx2: Est. $=2.1921, \mathrm{SE}=0.3536, \mathrm{z}=6.199, \mathrm{p}$ $<.0001$; NonEx1 versus NonEx2: Est. $=-1.7738, \mathrm{SE}=0.1340, \mathrm{z}=-13.238, \mathrm{p}<.0001)$. 'NonEx1' (e.g. *Spitzung) items elicited the highest error rates at $61 \%$. These were significantly higher than in 'NonEx2' (*Hübschung) items, where the error rate was $21 \%$.

\section{Discussion}

The general patterns observed in the prime analyses in Experiments 1,2 and 3 were replicated in Experiment 4. Control non-existent nonwords such as *Plümpang elicited faster reaction times and significantly lower error rates than the two sets of morphologically possible pseudowords. For the two sets of possible pseudowords, no differences in reaction times were discernible, but items like *Spitzung showed significantly higher error rates. That is, the 'NonEx1' items were more difficult to reject since the adjective and the intermediate verb exist, which is consistent with the idea that these complex pseudowords are felt to be more 'word-like' and are in fact more likely to become real words given the proximity to an existing lexical representation within the derivational chain. It appears that while any complex pseudoword that obeys morphological constraints can be decomposed to activate its base word, speakers are nonetheless sensitive to the lexical composition within derivational chains. 


\section{General discussion}

The research presented in this series of experiments provides evidence for speakers' sensitivity to morphological complexity in both two-step derived real words and plausible complex novel nouns. We defined plausible novel words as those which conform to the morphological rules of the language, but which are essentially lexical gaps. Thus, spitz $_{A D J E C T I V E}$

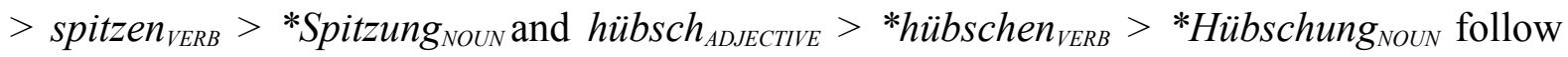
the morphological rules of deriving nouns with the addition of the suffix -ung via verbs formed from adjectives with the inflectional suffix -en. Consequently, they are plausible derivations. The two forms differ, because in the latter the intermediate verb does not exist, while in the former the verb is a real word.

In Experiments 1 and 2, we were able to establish decomposition for multi-suffixed complex words such as Heilung, as well as for the two sets of possible pseudowords *Spitzung and *Hübschung, since they all successfully primed their adjectival base. In principle, then, complex pseudowords containing lexical gaps in their derivational chain can be decomposed. This provides stronger evidence for decompositional, rather than 'full-form' storage accounts of morphological access. More specifically, it appears that the decomposition of the pseudoword primes leads to the activation of the base word (spitz or hübsch), which can successfully prime a later occurrence of the same base word. For existing morphologically related words, it has been shown previously that complex primes are decomposed into their constituent structures (Stanners, Neiser, Hernon, \& Hall, 1979). The present findings suggest that this process of decomposition is not restricted to existing words, but can extend to complex pseudowords like *Spitzung and *Hübschung. Recall that in Experiments 1 and 2, the *Spitzung and *Hübschung sets were kept separate. In the next step, we combined the two sets to examine the extra processing costs (if any) for novel forms where the intermediate step was missing; i.e. possible differences between *Spitzung and 
*Hübschung. In Experiment 3, as both sets of novel words are morphologically viable, we included a morphologically unviable type of pseudoword as an additional control. These items like *Steillein are not the result of a viable morphological rule of German (labelled as 'Control NonEx'), similarly to the *sportation items in Longtin and Meunier (2005). Experiment 3 showed that only morphologically viable formations activated their base forms and no priming occurred for the unviable items. Semantic and form-related controls in Experiment 3 did not prime, thus suggesting that the morphological priming effect was not driven by semantic or orthographic similarity alone.

Crucially, however, although both morphologically viable novel words showed priming, they were significantly different from each other. Pseudowords such as *Spitzung, where the intermediate form is a real word, led to a significantly stronger priming effect than the *Hübschung set. Further asymmetries in the processing between the two sets of possible pseudowords were also found in the prime error rate analyses in Experiments 3 and 4. The items in the *Spitzung set consistently elicited higher error rates than items such as *Hübschung, suggesting that these items were felt to be more 'word-like' by participants even though both sets were classified as nonwords in off-line tasks. These results are compatible with earlier accounts of pseudoword processing that found high error rates for affixed pseudowords in lexical decision tasks (e.g. Taft \& Forster, 1975). Complex pseudowords such as *dejuvenate for which stripping the affix de-results in the retrieval of an existing morpheme juvenate yielded higher error rates than *depertoire for which no existing morpheme pertoire is available. In our case, although superficially both sets of pseudowords are similar and the stem exists in both cases, decomposition across the first lexical gap in *Spitzung directly activates an existing lexical representation. The path leading from a complex prime to the base is thus more direct. Although both sets of complex pseudowords prime their base forms, error rates as well as magnitude in priming suggest that 
the lack of an intermediate lexicalised derivation points to a pseudoword that is less 'wordlike'; i.e. *Hübschung (without intermediate *hübschen) causes less interference than *Spitzung (with intermediate *spitzen) in a simple lexical decision task, but leads to a processing cost in the activation of the base. This processing cost, as evidenced in a reduction of the priming magnitude, could arise due to a decrease in the level of lexical activation of the base when the intermediate form is not lexicalised. That is to say, depending on the composition of the novel prime word and whether it is built based on an extant intermediate form or not, the degree of lexical activation received by the base differs. Items like *Spitzung for which the intermediate form is lexicalised could then allow increased activation to be passed on to the base. In combination with the findings reported by Taft and Forster (1975), our results are not compatible with models of morphological access in which the internal composition of complex items plays no role in word recognition.

Alternatively, it could be argued that items like *Spitzung, where an intermediate derivation exists, are more interpretable and therefore the more plausible novel form. Semantic interpretability is, of course, an important factor. For any nonword to be parsed, it would have to be to some extent interpretable. Marelli and Baroni (2015) have demonstrated the importance of semantic interpretability for novel forms by showing that semantically interpretable, novel forms have more semantic neighbours. There can be a number of reasons why a novel word has more semantic neighbours and is felt to be more meaningful. Meunier and Longtin (2007), for instance, showed that morphological legality is a prerequisite for semantic interpretability as only legal combinations of stems and suffixes ( ${ }^{\text {rapidifier }) \text { were }}$ judged to be semantically meaningful in off-line tasks. This was indeed the case for our novel words. However, both sets were equally legal in the way they were formed. The question arises then to what extent they differ in their morphological cohort and whether additional meaningfulness could result from the presence of a larger morphological cohort. That is, does 
one set have a bigger morphological cohort: e.g. more prefixed and suffixed words with the same stem such as zuspitzen (V., 'to point'), aufhübschen (V., 'to embellish')? Since we had controlled for morphological family size (see discussion of the stimuli set), the differences in priming and errors could not result from the size alone. Thus, the semantic interpretability must arise from within the derivational chain; the presence of spitzen in all likelihood increases the meaningfulness of *Spitzung in comparison to *Hübschung, which lacks an intermediate verb. Indeed, Marelli and Baroni's stimuli suggest that the low and high interpretability of some of their stimuli could actually be linked to derivational depth (compare hike $e_{V E R B}>$ hike $e_{\text {NOUN }}>*$ hikeless ADJECTIVE $_{\text {and }}$ acne $e_{\text {NOUN }}>*$ acneless $_{\text {ADJECTIVE }}$ where the nominal base in *hikeless is arguably already complex).

We also considered whether the high number of incorrectly classified primes in the 'NonEx1' condition (e.g. *Spitzung), suggesting that these pseudowords were processed like real words, led to the difference in the priming effect between the two conditions. That is to say, did the fact that *Spitzung was reacted to incorrectly as a word lead to more priming? This was not the case; the reaction to the stem targets, and thus the priming effect, was unrelated to the classification of the novel word primes. Recall that de Vaan et al. (2007) noticed that only when neologisms such as *lobbigkeit were classified as words did they lead to identity priming. Note that in our case, we were not investigating identity priming as a measure of a nascent frequency effect in neologisms. De Vaan et al.'s (2007) study, on the other hand, is not specifically concerned with the morphological analysis of neologisms and their internal composition. Moreover, the target word in de Vaan et al. (2007) for which a priming effect is established is always a nonword, whereas in the present experiment we find the more canonical case of measuring a priming effect for responses to targets that are existing words. These differences in experimental design and the comparisons on which the analyses rest can be advanced as possible explanations as to why the response to the prime 
word affects the target differently across the two studies. In our study, novel complex forms were decomposed both when the whole form was classified as a word and as a nonword.

In summary, novel words which look similar on the surface may have different derivational paths. *Spitzung is derived via two well-formed attested words spitz $>$ spitzen; meanwhile *Hübschung, although similar in shape, lacks a verb *hübschen, but the adjective hübsch exists. A series of experiments show differences in the two sets of novel nouns. Overall, our results are not compatible with 'full-listing' accounts of morphological processing and access (cf. Butterworth, 1983). Instead, morphologically complex novel forms are decomposed to their base as predicted under a decompositional account (e.g. Taft \& Forster, 1975). At the same time, the results are not reducible to an automatic affix-stripping procedure as has been previously reported in the masked priming literature. As Orfanidou, Davis and Marslen-Wilson (2011) suggest, during later stages of morphological processing, morpho-orthographic mechanisms are replaced by semantically-informed processes. In our case, this means that the visual recognition of complex words is modulated by subtle properties of the derivational chain, such as the lexicality of intermediate positions within the derivation. Taken together with the results obtained by Meinzer et al. (2009) and Pliatsikas et al. (2014), where despite lack of overt affixation, increased morphological complexity correlated with processing cost, our results indicate that speakers are not only sensitive to the number of derivations required to arrive at an extant complex word, but also to different degrees of morphological violation in derivational paths. 


\section{Acknowledgements}

The work was supported by an ESRC Doctoral Training Grant awarded to Swetlana Schuster (ES/767 J500112/1) and by an ERC Advanced Investigator grant (MORPHON 695481) awarded to Aditi Lahiri. We would like to thank Henning Reetz for organising the experiments at the University of Frankfurt and Colin Brooks for his helpful comments on previous versions of this manuscript. We would also like to thank the participants of the $52^{\text {nd }}$ Annual Chicago Linguistic Society and the Berkeley Germanic Linguistics Roundtable 2016 for their helpful comments on preliminary findings that formed the basis for the present research. 


\section{References}

Bates, D., Kliegl, R., Vasishth, S., \& Baayen, H. (2015). Parsimonious mixed models. http://arxiv.org/abs/1506.04967,MS.,arXiv, June 2015.

Bauer, L., Lieber, R., \& Plag, I. (2013). The Oxford Reference Guide to English Morphology. Oxford: Oxford University Press.

Bentin, S., \& Feldman, L. (1990). The contribution of morphological and semantic relatedness to repetition priming at short and long lags: Evidence from Hebrew. The Quarterly Journal of Experimental Psychology Section A, 42(4), 693711.

Booij, G. (2012). The Grammar of Words. Oxford: Oxford University Press.

Bozic, M., Marslen-Wilson, W., Stamatakis, E., Davis, M., \& Tyler, L. (2007). Differentiating Morphology, Form, and Meaning: Neural Correlates of Morphological Complexity. Journal of Cognitive Neuroscience, 19(9), 1464-1475. http://dx.doi.org/10.1162/jocn.2007.19.9.1464

Butterworth, B. (1983). Lexical representation. In B. Butterworth (Ed.), Language production Vol. 2 (pp. 257-294). London: Academic Press.

Clahsen, H., Sonnenstuhl, I., \& Blevins, J. (2002). Derivational morphology in the German mental lexicon (1st ed.). Colchester: Dept of Language and Linguistics, University of Essex. 
Crepaldi, D., Rastle, K., \& Davis, C. (2010). Morphemes in their place: Evidence for position-specific identification of suffixes. Memory \& Cognition, 38(3), 312-321. http://dx.doi.org/10.3758/mc.38.3.312

de Vaan, L., Schreuder, R., \& Baayen, R. (2007). Regular morphologically complex neologisms leave detectable traces in the mental lexicon. The Mental Lexicon, 2(1), 123. http://dx.doi.org/10.1075/ml.2.1.02vaa

Drews, E., \& Zwitserlood, P. (1995). Morphological and orthographic similarity in visual word recognition. Journal of Experimental Psychology: Human Perception and Performance, 21(5), 1098-1116. http://dx.doi.org/10.1037//0096-1523.21.5.1098

Feldman, L., \& Moskovljevic, J. (1987). Repetition priming is not purely episodic in origin. Journal of Experimental Psychology: Learning, Memory and Cognition, 13(4), 573581. http://dx.doi.org/10.1037//0278-7393.13.4.573

Fleischer, W. (1975). Wortbildung der deutschen Gegenwartssprache. Tübingen: Niemeyer.

Henderson, L., Wallis, J., \& Knight, D. (1984). Morphemic structure and lexical access. In H. Bouma \& D. Bouhuis (Eds.), Attention and Performance (Vol. X, pp. 211-225). London: Erlbaum. 
Joanisse, M., \& Seidenberg, M. (1999). Impairments in verb morphology after brain injury: A connectionist model. Proceedings of the National Academy of Sciences, 96(13), 7592-7597.

Kazanina, N., Dukova-Zheleva, G., Geber, D., Kharlamov, V., \& Tonciulescu, K. (2008). Decomposition into multiple morphemes during lexical access: A masked priming study of Russian nouns. Language and Cognitive Processes, 23(6), 800-823. http://dx.doi.org/10.1080/01690960701799635

Kouider, S., \& Dupoux, E. (2009). Episodic accessibility and morphological processing: Evidence from long-term auditory priming. Acta Psychologica, 130(1), 38-47.

Lahiri, A., \& Reetz, H. (2010). Distinctive features: Phonological underspecification in representation and processing. Journal of Phonetics, 38(1), 44-59. http://dx.doi.org/10.1016/j.wocn.2010.01.002

Longtin, C., \& Meunier, F. (2005). Morphological decomposition in early visual word processing. Journal of Memory and Language, 53(1), 26-41. http://dx.doi.org/10.1016/j.jml.2005.02.008

Marelli, M., \& Baroni, M. (2015). Affixation in semantic space: Modeling morpheme meanings with compositional distributional semantics. Psychological Review, 122(3), 485-515. http://dx.doi.org/10.1037/a0039267 
Marian, V., Bartolotti, J., Chabal, S., \& Shook, A. (2012). CLEARPOND: Cross-linguistic easy-access resource for phonological and orthographic neighborhood densities. PLoS ONE, 7(8), e43230.

Marslen-Wilson, W., \& Tyler, K. (1998). Rules, representations, and the English past tense. Trends in Cognitive Sciences 2(11), 428-35.

Marslen-Wilson, W. (2007). Morphological processes in language comprehension. In G. Gaskell (Ed.), Oxford Handbook of Psycholinguistics (pp.175-93). Oxford: Oxford University Press.

Marslen-Wilson, W., Tyler, L., Waksler, R., \& Older, L. (1994). Morphology and meaning in the English mental lexicon. Psychological Review, 101(1), 3-33.

Meunier, F., \& Longtin, C. (2007). Morphological decomposition and semantic integration in word processing. Journal of Memory and Language, 56(4), 457-471. http://dx.doi.org/10.1016/j.jml.2006.11.005

Meinzer, M., Lahiri, A., Flaisch, T., Hannemann, R., \& Eulitz, C. (2009). Opaque for the reader but transparent for the brain: Neural signatures of morphological complexity. Neuropsychologia, 47(8-9), 1964-1971. 
Morris, J., Porter, J., Grainger, J., \& Holcomb, P. (2011). Effects of lexical status and morphological complexity in masked priming: An ERP study. Language and $\begin{array}{llr}\text { Cognitive } & \text { Processes, } & \text { 26(4-6), }\end{array}$ http://dx.doi.org/10.1080/01690965.2010.495482

Napps, S., \& Fowler, C. (1987). Formal relationships among words and the organization of the mental lexicon. Journal of Psycholinguistic Research, 16(3), 257272.

Orfanidou, E., Davis, M., \& Marslen-Wilson, W. (2011). Orthographic and semantic opacity in masked and delayed priming: Evidence from Greek. Language and Cognitive Processes, 26(4-6), 530-557. http://dx.doi.org/10.1080/01690965.2010.509055

Pinker, S. \& Ullman, M. (2002). The past and future of the past tense. Trends in Cognitive Sciences, 6(11), 456-463.

Plag, I., \& Baayen, H. (2009). Suffix Ordering and Morphological Processing. Language, 85(1), 109-152. http://dx.doi.org/10.1353/lan.0.0087

Pliatsikas, C., Wheeldon, L., Lahiri, A., \& Hansen, P. (2014). Processing of zero-derived words in English: An fMRI investigation. Neuropsychologia, 53, 47-53.

Rastle, K., Davis, M., \& New, B. (2004). The broth in my brother's brothel: Morphoorthographic segmentation in visual word recognition. Psychonomic Bulletin \& Review, 11(6), 1090-1098. 
Reetz, H., \& Kleinmann, A. (2003). Multi-subject hardware for experiment control and precise reaction time measurement. In Proceedings of the 15th International Congress of Phonetic Sciences, M.J. Solé, D. Recasens, \& J. Romero, eds., Barcelona, 1489-92.

Scharinger, M., Reetz, H., \& Lahiri, A. (2009). Levels of regularity in inflected word form processing. The Mental Lexicon, 4(1), 77-114. http://dx.doi.org/10.1075/ml.4.1.04sch

Stanners, R., Neiser, J., Hernon, W., \& Hall, R. (1979). Memory representation for morphologically related words. Journal of Verbal Learning and Verbal Behavior, 18(4), 399-412. http://dx.doi.org/10.1016/s0022-5371(79)90219-6

Taft, M., \& Forster, K. (1975). Lexical storage and retrieval of prefixed words.

Journal of Verbal Learning and Verbal Behavior, 14(6), 638647.doi:10.1016/s0022-5371(75)80051-x

Yap, M., Sibley, D., Balota, D., Ratcliff, R., \& Rueckl, J. (2015). Responding to nonwords in the lexical decision task: Insights from the English Lexicon Project. Journal of Experimental Psychology: Learning, Memory, and Cognition, 41(3), 597-613. http://dx.doi.org/10.1037/xlm0000064 


\section{Tables and Figures}

\begin{tabular}{c|c|c|c}
\hline Condition & Example stimuli & Derivational & Type of violation \\
\hline Extant: & Heilung (N, 'healing') & heil - & No violation \\
$\{+$ Morph; + Extant noun; & & heilen - & \\
+ Extant intermediate & & Heilung & \\
derivation $\}$ & & spitz - & Over-application of \\
\hline NonEx1: & & spitzen - & one derivation to a \\
$\{+$ Morph; - Extant noun; & & $*$ Spitzung & non-existent item \\
+ Extant intermediate & & & \\
\hline
\end{tabular}

Table 1. Overview of test stimuli in Experiment 1 


\begin{tabular}{c|c|c|c}
\hline Condition & Example stimuli & Derivational & Type of violation \\
& & pattern & \\
\hline Extant: & Heilung (N, 'healing') & heil - & No violation \\
$\begin{array}{c}\text { \{ Morph; + Extant noun; } \\
+ \text { Extant intermediate }\end{array}$ & & heilen - & \\
derivation $\}$ & & & \\
\hline NonEx2: & Heilung & \\
$\{+$ Morph; - Extant & 'beautifying') & $*$ hübschen - & two derivations to two \\
noun; - Extant & & $*$ Hübschung & non-existent items \\
intermediate derivation $\}$ & & & \\
\hline
\end{tabular}

Table 2. Overview of test stimuli in Experiment 2 


\begin{tabular}{|c|c|c|c|c|}
\hline & \multicolumn{2}{|c|}{ Extant Condition } & \multicolumn{2}{|c|}{ NonEx1 Condition } \\
\hline $\begin{array}{l}\text { Related } \\
\text { Prime }\end{array}$ & $\begin{array}{c}\text { Heilung } \\
\text { (N., 'healing') }\end{array}$ & $\begin{array}{c}\text { Teilbarkeit } \\
\text { (N., 'divisibility') }\end{array}$ & $\begin{array}{c}\text { *Spitzung } \\
\text { (N., 'sharpening') }\end{array}$ & $\begin{array}{c}\text { *Denkbarkeit } \\
\text { (N., 'thinkability') }\end{array}$ \\
\hline $\begin{array}{c}\text { Unrelated } \\
\text { Prime }\end{array}$ & $\begin{array}{c}\text { Faultier } \\
\text { (N., 'sloth'; extant } \\
\text { complex word; } \\
\text { unrelated to root } \\
\text { heil) }\end{array}$ & $\begin{array}{l}\text { Abstreicher } \\
\text { (N., 'doormat'; } \\
\text { extant complex } \\
\text { word; unrelated to } \\
\text { root in teilen) }\end{array}$ & $\begin{array}{c}\text { *Dürrung } \\
\text { (N., 'act of becoming } \\
\text { thin'; } \\
\text { non-existent complex } \\
\text { word; unrelated to } \\
\text { root in spitz) }\end{array}$ & $\begin{array}{c}\text { *Förderkeit } \\
\text { (N., 'possibility of } \\
\text { sponsoring'; } \\
\text { non-existent complex } \\
\text { word; unrelated to the } \\
\text { root in denken) }\end{array}$ \\
\hline $\begin{array}{c}\text { Intermediate } \\
\text { form }\end{array}$ & $\begin{array}{c}\text { heilen } \\
\text { (V., 'heal') }\end{array}$ & $\begin{array}{c}\text { teilbar } \\
\text { (A., 'divisible') }\end{array}$ & $\begin{array}{c}\text { spitzen } \\
\text { (V., 'sharpen') }\end{array}$ & $\begin{array}{c}\text { denkbar } \\
\text { (A., 'thinkable') }\end{array}$ \\
\hline Target & $\begin{array}{c}\text { heil } \\
\text { (A., 'whole, safe') }\end{array}$ & $\begin{array}{c}\text { teilen } \\
\text { (V., 'divide') }\end{array}$ & $\begin{array}{c}\text { spitz } \\
\text { (A., 'sharp') }\end{array}$ & $\begin{array}{c}\text { denken } \\
\text { (V., 'think') }\end{array}$ \\
\hline
\end{tabular}

Table 3. Examples of stimuli for test conditions 'Extant' and 'NonEx1' with their related and unrelated primes, the intermediate derivational position and the target words 


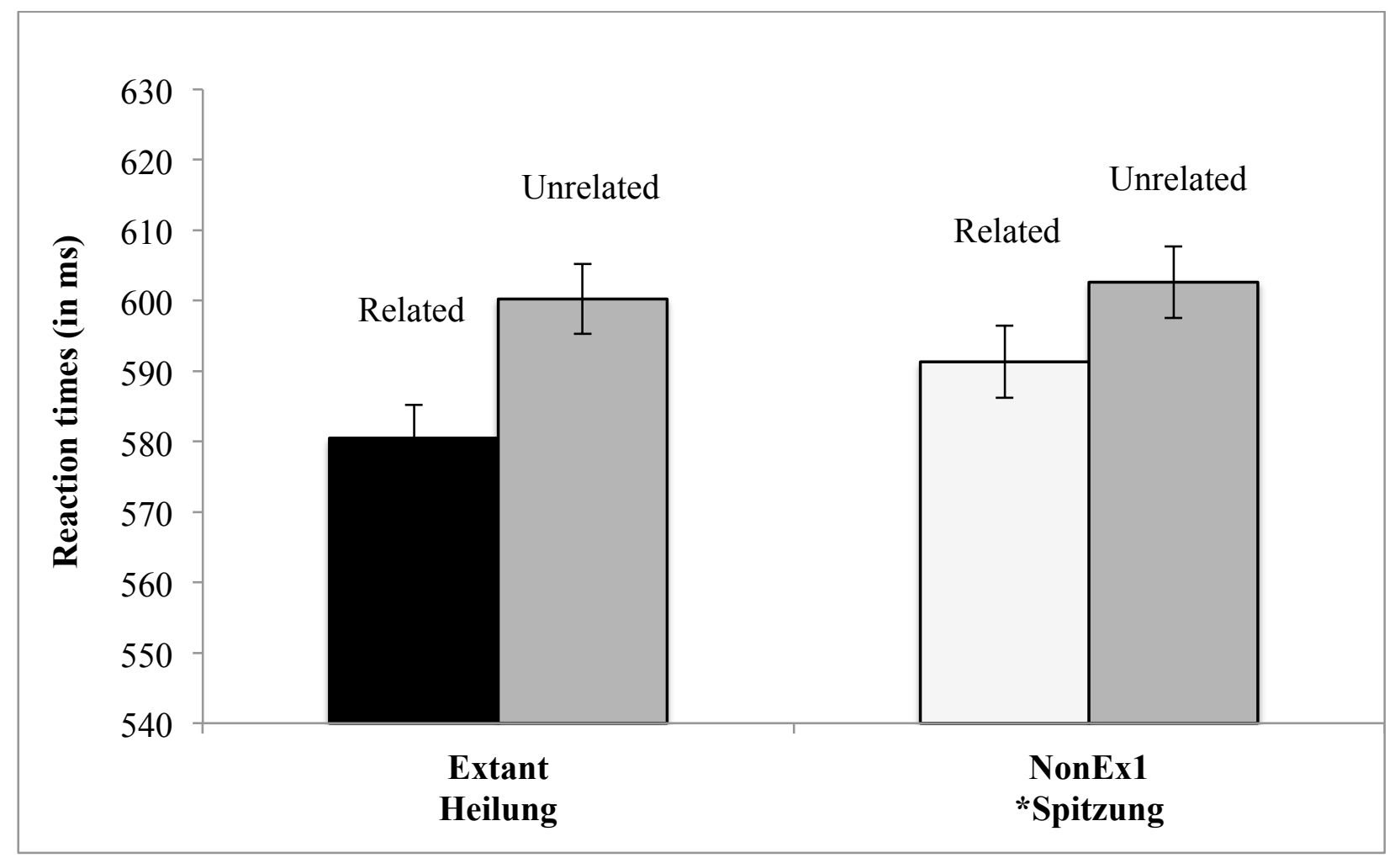

Figure 1. Reaction times to targets in test conditions (Experiment 1). 


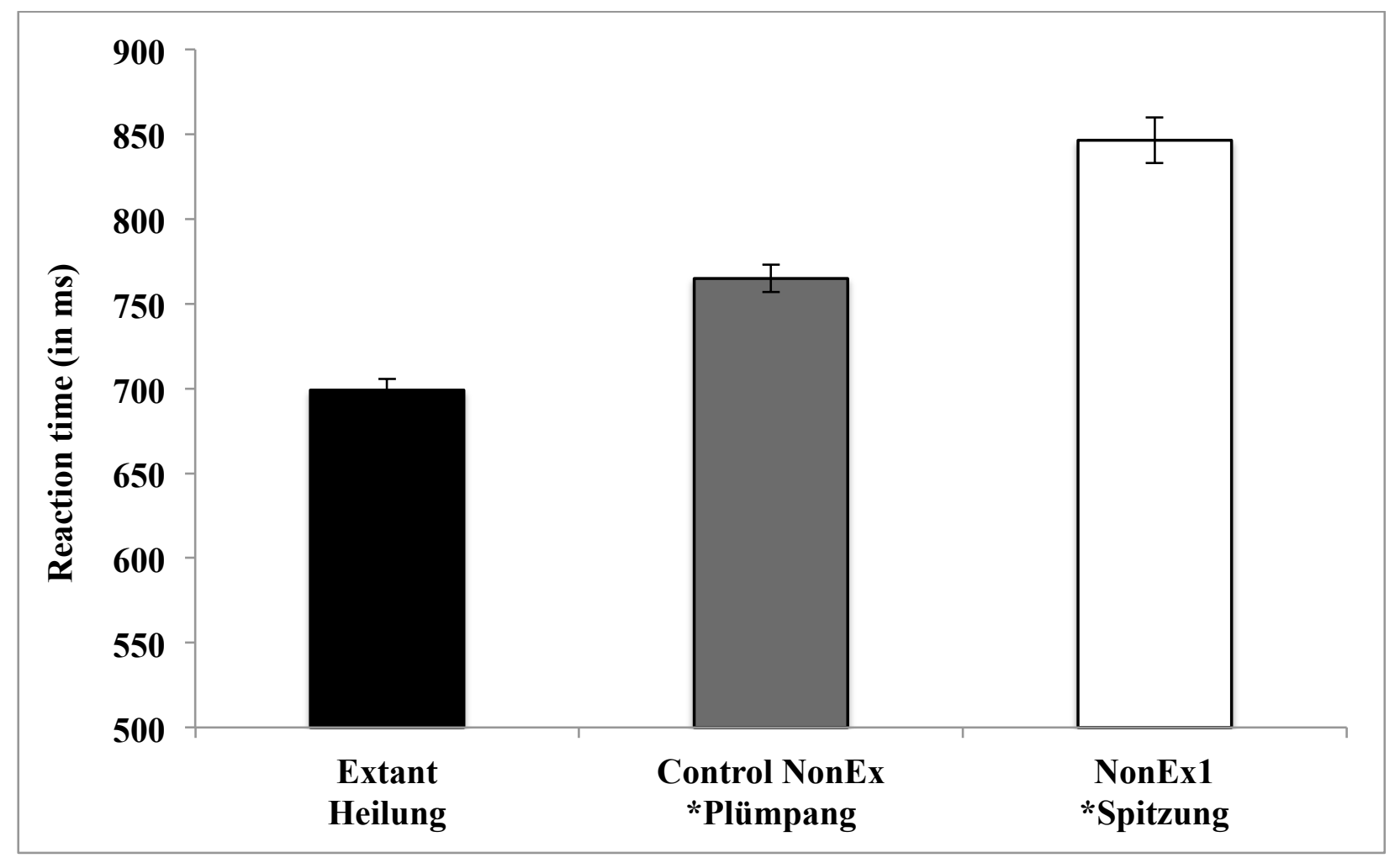

Figure 2. Mean reaction times to primes (Experiment 1) 


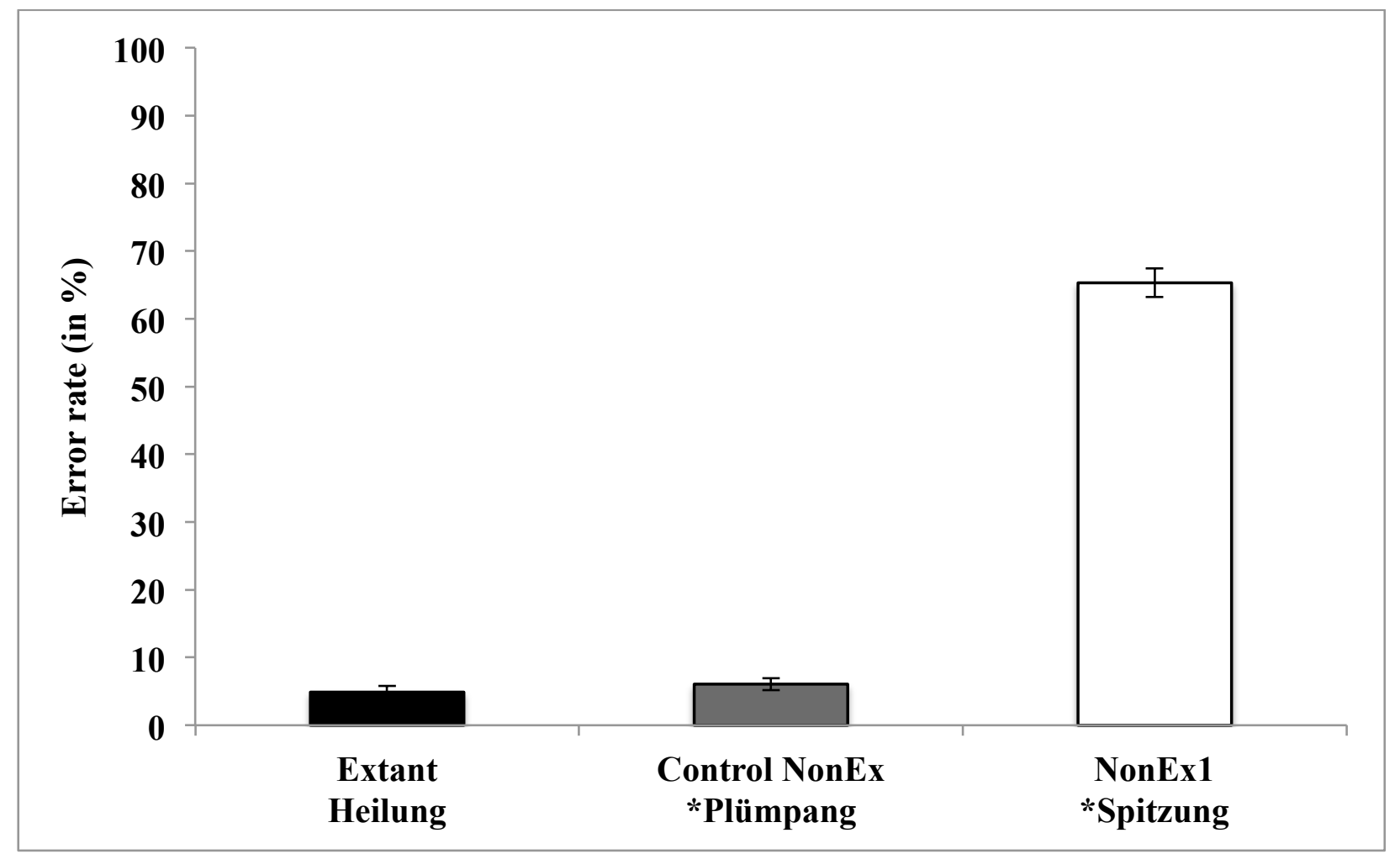

Figure 3. Error rates to primes (Experiment 1) 


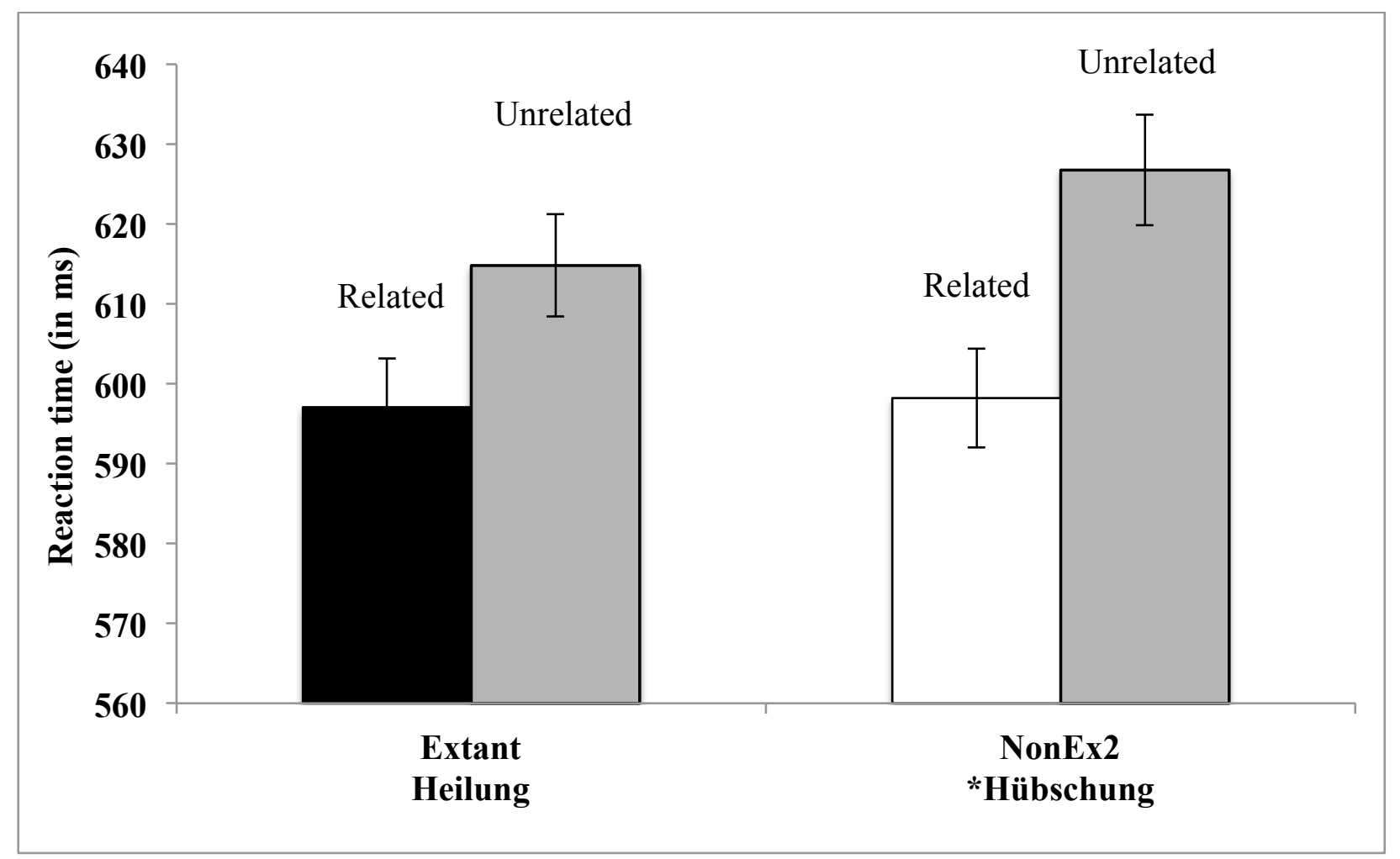

Figure 4. Reaction times to targets in test conditions (Experiment 2). 


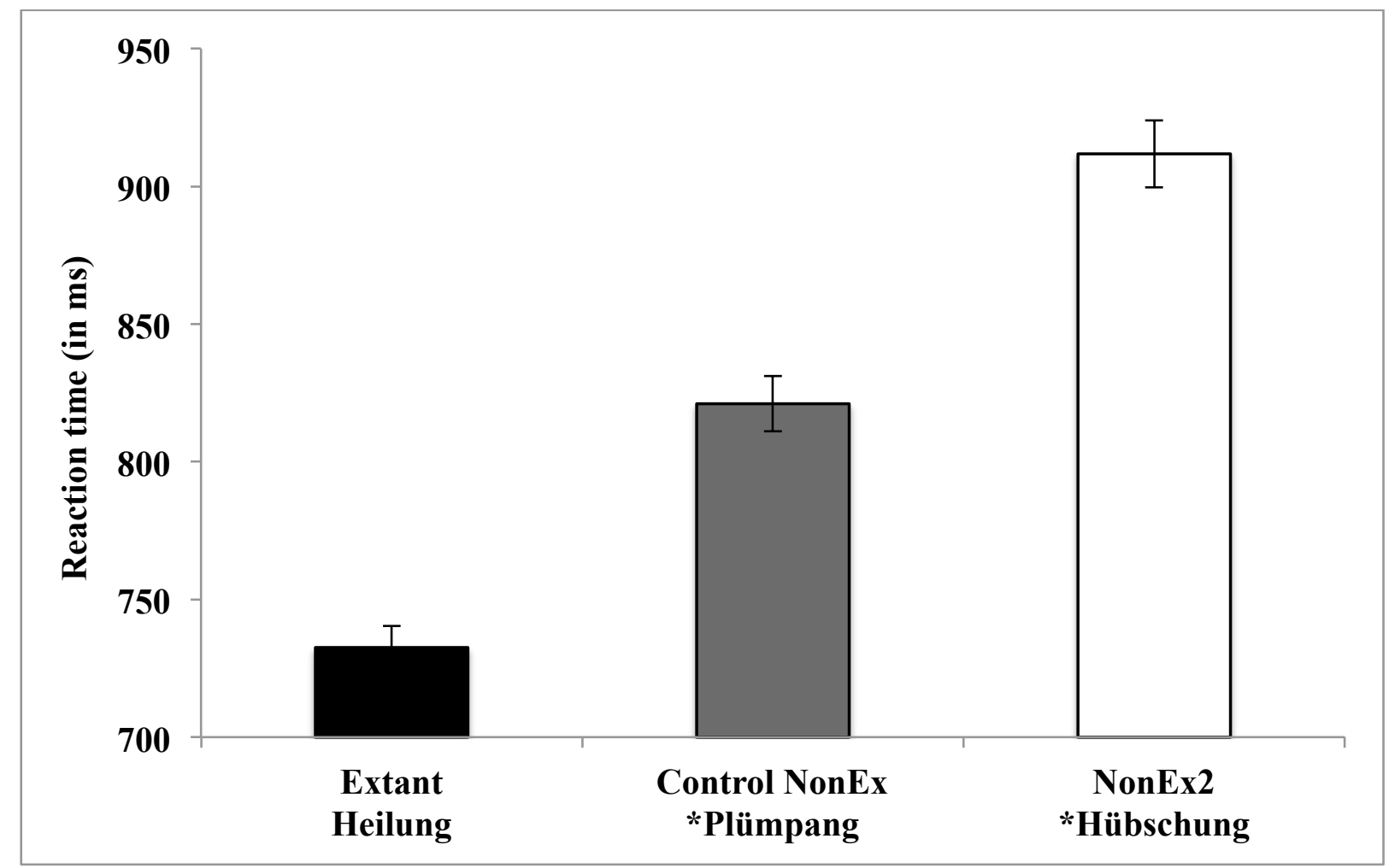

Figure 5. Mean reaction times to primes in conditions 'Extant' versus 'Control NonEx' versus 'NonEx2' (Experiment 2) 


$$
= \pm
$$




\begin{tabular}{|c|c|c|c|c|c|c|}
\hline & Extant & NonEx1 & NonEx2 & Form Control & Form Control & Semantic control \\
& & & Extant & NonEx & \\
\hline Rel & 598.48 & 612 & $617.26 \pm$ & 653.41 & 659.17 & \pm 18.44 \\
& \pm 116.54 & \pm 124.84 & 130.43 & \pm 142.25 & \pm 146.9 & $(0.29)$ \\
\hline Unr & $(0.26)$ & $(0.26)$ & $(0.26)$ & $(0.29)$ & 662.5 & $618.35 \pm 116.68$ \\
& \pm 27.35 & $646.92 \pm$ & $633.96 \pm$ & 650.76 & \pm 137.39 & $(0.75)$ \\
& \pm 120.32 & 136.13 & 138.4 & \pm 130.01 & $(0)$ & $(0)$ \\
$(0)$ & $(0.54)$ & $(0.26)$ & $(0)$ & & \\
\hline
\end{tabular}

Table 4. Mean reaction times (with standard deviations) and error rates to targets (Experiment 3) 


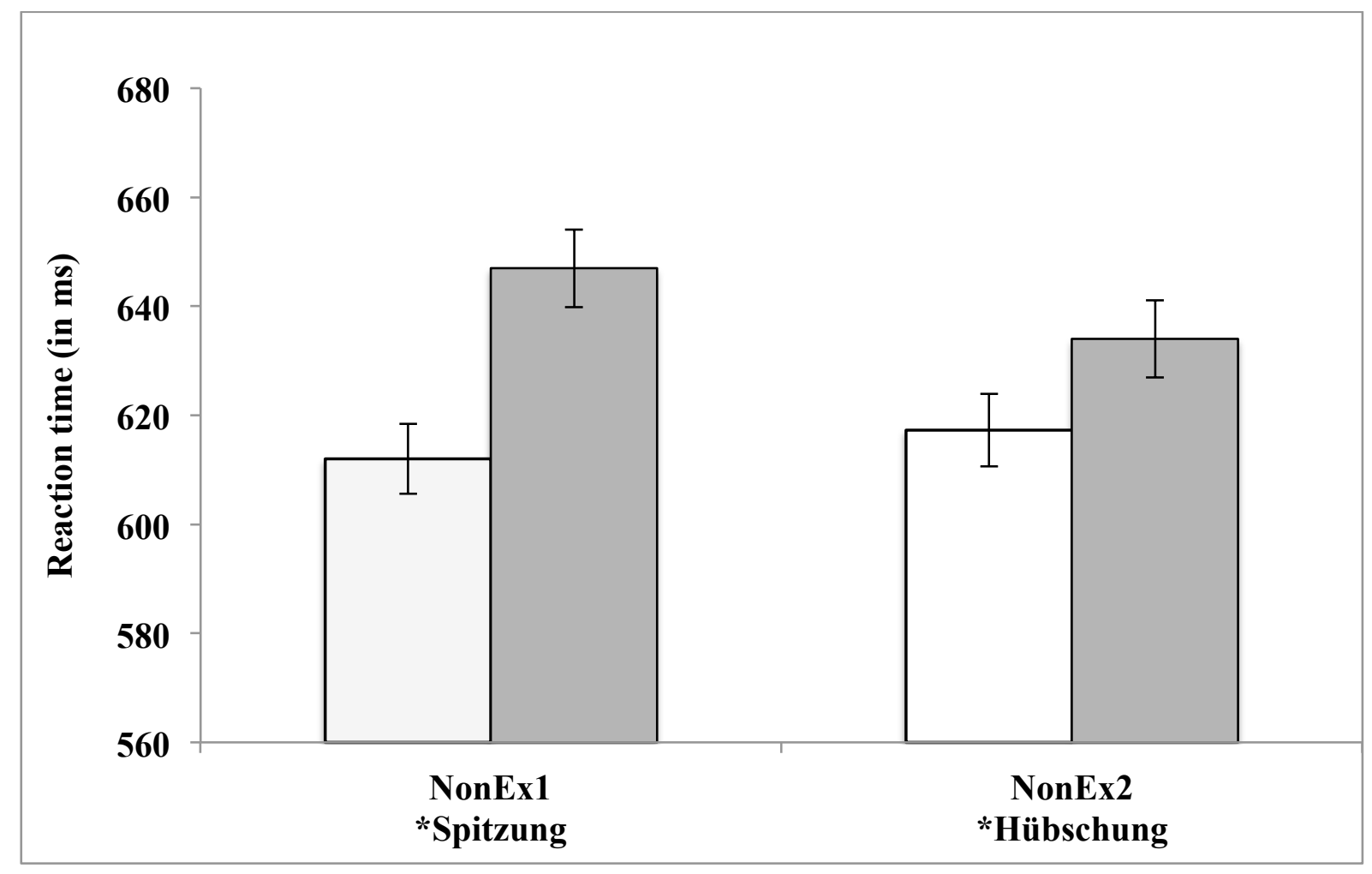

Figure 7. Reaction times to targets in conditions NonEx1 and NonEx2 (Experiment 3). 


\begin{tabular}{|l|l|l|l|l|}
\hline & Extant & NonEx1 & NonEx2 & Control NonEx \\
\hline Reaction time (ms) & $743.81(168.32)$ & $917.35(199.59)$ & $906.56(193.66)$ & $911.76(192.03)$ \\
\hline Error rate (\%) & 3.87 & 62.7 & 31.55 & 14.21 \\
\hline
\end{tabular}

Table 5. Mean reaction times (with standard deviations) and error rates to primes (Experiment 3) 


\begin{tabular}{|l|l|l|l|l|}
\hline & Extant & NonEx1 & NonEx2 & Control NonEx \\
\hline Reaction time (ms) & $785.46(184.71)$ & $934.62(177.09)$ & $927.30(180.00)$ & $878.10(198.75)$ \\
\hline
\end{tabular}

Table 6. Mean reaction times and standard deviations in all conditions (Experiment 4) 


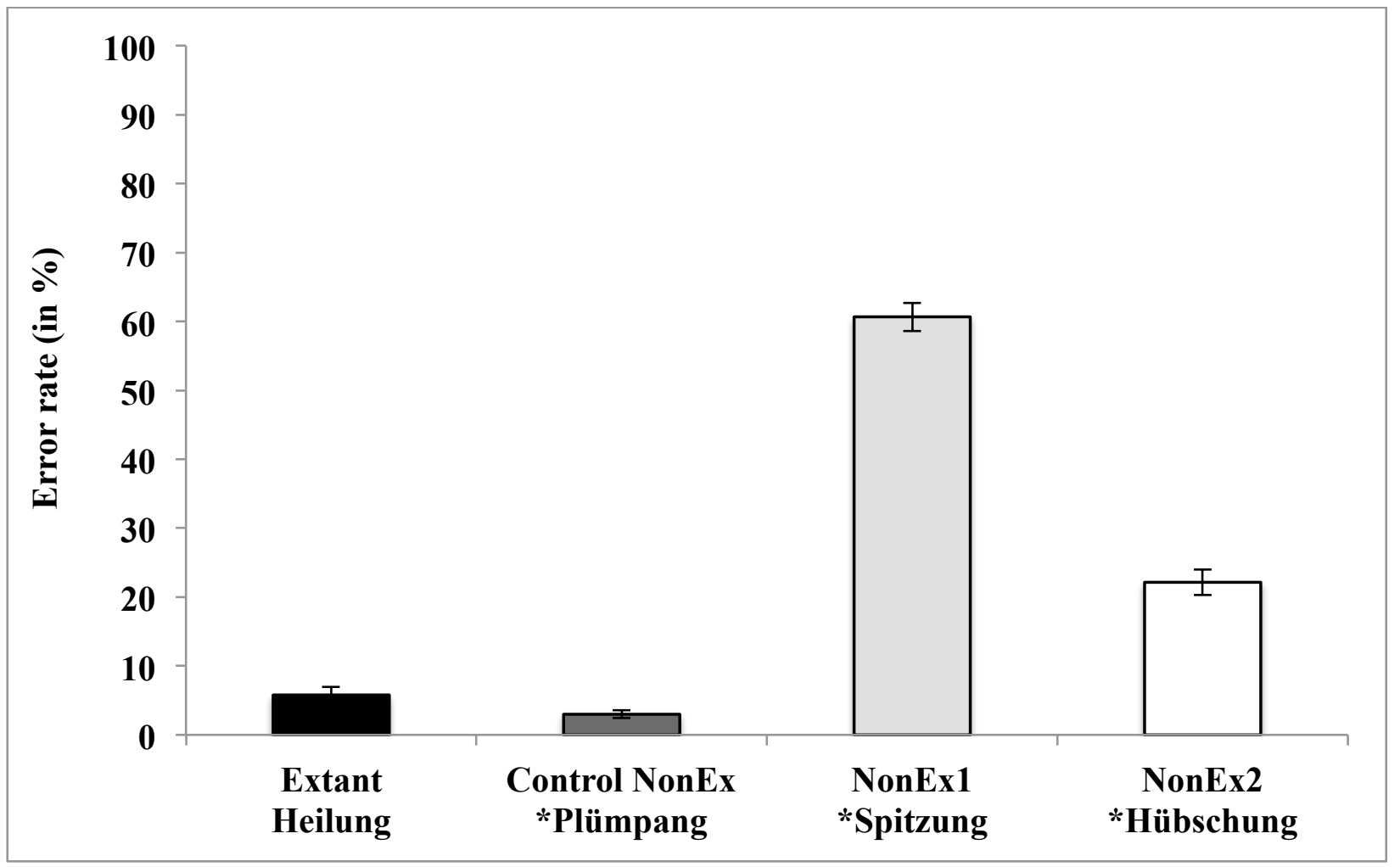

Figure 8. Error rates in test conditions (Experiment 4) 